\title{
Predictors of Treatment Attendance and Adherence among Individuals Receiving Cognitive Behavioral Therapy for Insomnia
}

Ruifeng Cui

Follow this and additional works at: https://researchrepository.wvu.edu/etd

\section{Recommended Citation}

Cui, Ruifeng, "Predictors of Treatment Attendance and Adherence among Individuals Receiving Cognitive Behavioral Therapy for Insomnia" (2017). Graduate Theses, Dissertations, and Problem Reports. 5416. https://researchrepository.wvu.edu/etd/5416

This Thesis is protected by copyright and/or related rights. It has been brought to you by the The Research Repository @ WVU with permission from the rights-holder(s). You are free to use this Thesis in any way that is permitted by the copyright and related rights legislation that applies to your use. For other uses you must obtain permission from the rights-holder(s) directly, unless additional rights are indicated by a Creative Commons license in the record and/ or on the work itself. This Thesis has been accepted for inclusion in WVU Graduate Theses, Dissertations, and Problem Reports collection by an authorized administrator of The Research Repository @ WVU. For more information, please contact researchrepository@mail.wvu.edu. 
Predictors of Treatment Attendance and Adherence Among Individuals Receiving Cognitive Behavioral Therapy for Insomnia

\author{
Ruifeng Cui
}

Thesis submitted

to the Eberly College of Arts and Sciences

at West Virginia University

in partial fulfillment of the requirements for the degree of

Master of Science in

Psychology

\begin{abstract}
Amy Fiske, Ph.D., Chair
Daniel W. McNeil, Ph.D.

Nicholas Turiano, Ph.D.

Department of Psychology
\end{abstract}

Morgantown, West Virginia

2017

Keywords: insomnia, treatment, attendance, adherence

Copyright 2017 Ruifeng Cui 


\author{
ABSTRACT \\ Predictors of Treatment Attendance and Adherence Among Individuals Receiving \\ Cognitive Behavioral Therapy for Insomnia

\section{Ruifeng Cui}

Rates of Insomnia Disorder have been found to be as high as $10 \%$ in the general population. Cognitive Behavioral Therapy for Insomnia (CBT-I) is an effective treatment for insomnia. Problematically, low rates of treatment attendance and adherence are common in CBT-I and negatively impact treatment outcomes. The present study examined predictors of attendance and adherence in a sample of adults receiving CBT-I. Identifying common predictors may help researchers in designing more effective CBT-I treatments. Participants were 108 community dwelling adults aged 19-95 who met criteria for Insomnia Disorder. The sample was comprised of primarily female $(71.3 \%)$ middle age $(M=50.5, S D=14.6)$, Caucasian $(92.6 \%)$ adults. Younger adults and adults with greater depression and anxiety symptoms were less likely to attend three or more sessions or complete CBT-I treatment. Additionally, younger adults were less likely to adhere to a consistent bed time and wake time, i.e., younger adults had greater variation in when they first went to bed at night and got out of bed in the morning. The present study found that younger adults and those with greater comorbid psychiatric symptom severity (i.e., depression and anxiety symptoms) were less likely to attend CBT-I treatment. Further, among patients who attended CBT-I treatment, younger adults were less likely to adhere consistently to a recommended bed time and wake time. Assessing for and addressing elevated depression and anxiety levels prior to CBT-I treatment may facilitate treatment attendance. Future research may investigate mediators of the relationship between age and CBT-I treatment utilization. 


\section{TABLE OF CONTENTS}

$\begin{array}{ll}\text { Introduction } & 1\end{array}$

$\begin{array}{ll}\text { Treatments for insomnia } & 2\end{array}$

Attendance and adherence in insomnia treatment 4

Behavioral Model of Health Care Utilization 6

$\begin{array}{ll}\text { Predictors of treatment attendance and adherence } & 7\end{array}$

$\begin{array}{ll}\text { Statement of the problem and hypotheses } & 13\end{array}$

$\begin{array}{ll}\text { Method } & 15\end{array}$

$\begin{array}{ll}\text { Participants } & 16\end{array}$

$\begin{array}{ll}\text { Cognitive Behavioral Therapy for Insomnia } & 17\end{array}$

$\begin{array}{ll}\text { Measures } & 21\end{array}$

$\begin{array}{ll}\text { Analyses } & 26\end{array}$

$\begin{array}{ll}\text { Results } & 28\end{array}$

$\begin{array}{ll}\text { Sample characteristics } & 28\end{array}$

Predictors of attending three or more sessions $\quad 29$

Predictors of attending all recommended sessions $\quad 30$

$\begin{array}{ll}\text { Predictors of adherence to consistent bed time } & 31\end{array}$

Predictors of adherence to consistent wake time 32

$\begin{array}{ll}\text { Discussion } & 33\end{array}$

$\begin{array}{ll}\text { References } & 41\end{array}$

$\begin{array}{ll}\text { Tables } & 57\end{array}$

$\begin{array}{ll}\text { Figure } & 67\end{array}$

$\begin{array}{ll}\text { Appendices } & 68\end{array}$ 
Predictors of Treatment Attendance and Adherence Among Individuals Receiving Cognitive Behavioral Therapy for Insomnia

"Showing up is 80 percent of life," a quote commonly attributed to Woody Allen, succinctly describes the importance of effort, motivation, and literally showing up as it relates to success in life. The problem of not showing up is particularly relevant to the successful treatment of mental health disorders such as Insomnia Disorder. A meta-analysis conducted by Swift and Greenberg (2012) found that one out of every five clients prematurely discontinues psychotherapy. However, much higher rates of premature discontinuation have been found in clinical treatment studies for Insomnia Disorder (33\% Espie et al., 2008; 53\%, Espie et al., 2007; 34\%, Morgan, Thompson, Dixon, Tomeny, \& Mathers, 2003).

Insomnia is a prevalent problem among adults and older adults. Insomnia has been defined as having difficulty initiating sleep, maintaining sleep, or waking up too early despite having the opportunity to sleep with this difficulty causing significant distress or impairment in functioning (American Psychiatric Association, 2013). Insomnia rates of between 10-37\% have been found among individuals 18 and older (Morin, LeBlanc, Daley, Gregoire, \& Merette, 2006; Morphy, Dunn, Lewis, Boardman, \& Croft, 2007). Further, an epidemiological study conducted by Ohayon (2002) found that more than $50 \%$ of older adults (ages $65+$ ) suffer from symptoms of insomnia. Among individuals with insomnia, 25-33\% have primary insomnia while the rest have secondary insomnia, i.e. insomnia caused by another mental or physical illness (American Psychiatric Association, 2000; Espie et al., 2007; Roth \& Roehrs, 2003).

Insomnia has been linked to decreased productivity in the workplace, a lower quality of life, a greater economic burden, and an increased risk of mortality for individuals (Bolge, Doan, Kannan, \& Baran, 2009; Dew et al., 2003; Ozminkowski, Wang, \& Walsh, 2007). Insomnia has 
been found to be associated with a number of mental and physical illnesses (Taylor, Lichstein, \& Durrence, 2003; Taylor et al., 2007) as well as increased health care utilization (Daley et al., 2009). A treatment study conducted by Espie and colleagues (2007) found that $40 \%$ of participants had a co-occurring physical health problem and 58\% had a co-occurring mental health problem with the two most common mental disorders being depression and anxiety. Further, insomnia increases the risk of developing both depressive disorders (Cole, \& Dendukuri, 2003; Riemann \& Voderholzer, 2003) and anxiety disorders (Neckelmann, Mykletun, \& Dahl, 2007).

\section{Treatments for insomnia}

Pharmacotherapy is the most common treatment utilized by individuals suffering from insomnia (National Institutes of Health, 2005). A survey conducted by Leger and Poursain (2005) found that $95 \%$ of individuals in the United States who were severely impacted by their symptoms of insomnia consulted a physician and among those who consulted a physician, $95 \%$ were given a prescription for sleep medication. Although pharmacotherapy is effective at treating insomnia in the short term (Smith et al., 2002), there are problems with long term usage of medications for insomnia as some individuals develop a tolerance and insomnia often resumes after discontinuation of the medications (National institutes of Health, 2005; Tariq \& Pulisetty, 2008). Other downsides of pharmacological treatment include increased risk for accidents, especially when individuals take prescription sleep medications too late in the evening without sufficient opportunity to sleep (Gustavsen et al., 2008; Verster et al., 2002). Ambien, a common prescription medication for insomnia, is also on the Beers Criteria for Potentially Inappropriate Medication Use in Older Adults as its potential for harm greatly outweighs the limited benefits for improving insomnia (Samuel, 2015). 
A nonpharmacological option for treating insomnia is Cognitive Behavioral Therapy for Insomnia (CBT-I). CBT-I is a multicomponent treatment that targets the theorized underlying factors that perpetuate insomnia in individuals, e.g., engaging in activities in the bed besides sleep and sex which weakens the association between bed and sleep (stimulus dyscontrol), extending sleep opportunity which decreases sleep drive, poor sleep hygiene, catastrophic thoughts about consequences of poor sleep (Perlis, Jungquist, Smith, \& Posner, 2006). CBT-I typically consists of stimulus control and sleep restriction or compression. Stimulus control is used to strengthen the association between bed and sleep (i.e., don't engage in any activities in the bedroom except for sleep and sex and get out of bed after 15 minutes of being awake). Sleep restriction or compression is used to limit a person's sleep opportunity in order to consolidate their sleep (i.e., set a consistent bed and wake time for every day of the week that restricts their sleep opportunity). CBT-I also teaches clients sleep hygiene habits (e.g., create a comfortable sleeping environment, don't take naps in the daytime, etc.) and cognitive restructuring techniques to challenge catastrophic thoughts regarding failing to get a good night's sleep.

CBT-I is successful at treating insomnia among adults and older adults (Edinger \& Means, 2005; Irwin, Cole, \& Nicassio, 2006; Montgomery \& Dennis, 2004). A study conducted by Jacobs and colleagues (2004) demonstrated that CBT-I is more effective than pharmacotherapy at reducing sleep onset latency, increasing sleep efficiency, and sustaining treatment gains among adults. CBT-I has also been shown to be more effective than Zopiclone in improving sleep efficiency among older adults (Sivertsen et al., 2006). Additionally, CBT-I has been shown to be effective at treating secondary insomnia and insomnia comorbid with medical or physical health problems (Edinger et al., 2009; Kohn \& Espie, 2005; Morin et al., 2006; Stepanski \& Rybarczyk, 2006). CBT-I is preferred over pharmacotherapy by individuals with 
insomnia (Vincent \& Lionberg, 2001). Further, the National Institutes of Health, the American Academy of Sleep Medicine's Practice Parameters, and the American College of Physicians have endorsed CBT-I as the first line treatment for individuals with chronic primary insomnia (Qaseem, A., Kansagara, D., Forciea, M. A., Cooke, M., \& Denberg, T. D., 2016; Smith \& Perlis, 2006). Studies have found that, on average, patients receiving CBT-I experienced at least a $50 \%$ decrease in wake after sleep onset and a $26 \%$ to $65 \%$ decrease in sleep onset latency (Edinger \& Means, 2005). A group CBT-I treatment study by Backhaus and colleagues (2001) found that participants' sleep continued to improve after the end of treatment with their total sleep time increasing from 298 minutes at baseline to 351 minutes at end of treatment and 379 minutes by the one-year follow-up period. Another group CBT-I treatment study also found that total sleep time improved in the one year follow up period during which time $84 \%$ of participants who were using hypnotics at baseline were no longer using hypnotics (Espie, Inglis, Tessier, \& Harvey, 2001).

\section{Attendance and adherence in insomnia treatment}

Although CBT-I is an efficacious treatment for insomnia, the effectiveness of CBT-I is hindered by high rates of attrition during treatment. Past insomnia treatment research has defined attendance in different ways, such as a dichotomous variable specifying completion (attended all sessions) vs non-completion/dropout (failed to attend all sessions; Edinger, Wohlgemuth, Radtke, Marsh, \& Quillian, 2001) or a dichotomous variable specifying attendance at a specific, prerequisite number of sessions (e.g., four or more sessions, Ong et al., 2008), or a continuous variable of number of sessions attended (Morin et al., 1999). The most common attendance definition used is completing all treatment sessions. Low attrition rates have been found in many CBT-I efficacy studies (e.g., 92\% treatment completion rate, Edinger et al.,2001; 97\% average 
session attendance rate, Morin, Colecchi, Stone, Sood, \& Brink, 1999; 100\% treatment completion rate, Sivertsen et al., 2006) which typically use homogenous samples and have strict inclusion and exclusion criteria. Commonly excluded participants include those who are pregnant, have sleep apnea, have comorbid mental or medical disorders, who are using sleep aid medications, who are using psychiatric medications, and who are in psychotherapy. Clinical studies with less strict inclusion and exclusion criteria (e.g., allowing individuals with comorbid mental or physical illness and/or individuals using hypnotic medications to participate) have found higher rates of attrition (e.g., 67\% completion rate, Espie et al., 2008; 47\% attended 5 of the 5 sessions, Espie et al., 2007; $66 \%$ attended 6 of the 6 sessions, Morgan et al., 2003). The high rates of attrition found in CBT-I treatment studies utilizing more heterogeneous and generalizable samples is problematic because studies have shown that higher rates of attendance in CBT-I sessions is associated with better treatment outcomes (Edinger, Wohlgemuth, Radtke, Coffman, \& Carney, 2007; Espie et al., 2007).

Another potential problem in CBT-I treatment is patients' adherence to treatment recommendations. Studies using self-report ratings of treatment adherence have generally shown high self-reported treatment adherence (e.g., adhering to treatment recommendations 6 out of 7 days, Edinger et al., 2009; compliance rated a 4 on a 5 point scale; Morin et al., 1999; compliance rated 4.8 on a 5 point scale, Sivertsen et al., 2006). Although self-reported measures of adherence utilizing self-report rating scales are generally high, other measures of adherence have been less positive. Objective measurement of adherence has typically been defined as a continuous variable of variation in times that the participants got into bed at night with the intention of going to sleep and variation in times that the participant got up from bed for the last time with the intention of not returning to bed to sleep more (Riedel \& Lichstein, 2001; Vincent 
\& Hameed 2003). In a CBT-I group treatment study conducted by Vincent and Hameed (2003), only $48 \%$ of participants were rated by therapists as very much or extremely adherent to treatment. A study conducted by Riedel and Lichstein (2001) found that patients stayed in bed 28 minutes longer than prescribed. This is not surprising since participants have rated sleep restriction as their least favorable piece of CBT-I treatment (Vincent \& Lionberg, 2001). Adherence to CBT-I treatment recommendations is important as it is associated with better outcomes (Edinger \& Means, 2005; Riedel \& Lichstein, 2001; Vincent \& Hameed, 2003).

\section{Behavioral Model of Health Care Utilization}

Identifying predictors of health care utilization can allow researchers to design more effective CBT-I treatments with better rates of attendance and adherence. The Behavioral Model of Health Care Utilization created by Andersen (1995) has been used as a conceptual framework for organizing and investigating multiple variables related to treatment utilization. These variables are classified into three categories: predisposing, enabling, and need factors.

Predisposing factors are individual characteristics that predict an individual's utilization of treatment services. These factors include demographic related factors (e.g., age, gender) which represent stable biological and physical characteristics as well as social status related factors which indicate a person's status in their community (e.g., ethnicity, education), both of which may predispose them to be more likely to utilize treatment. A separate model consistent with the Andersen model is the Health Belief Model, which states that these demographic characteristics influence predisposition to utilize treatment by influencing an individual's perceived barriers to treatment utilization and/or perceived severity of disease (Martin, Haskard-Zolnierek, \& DiMatteo, 2010). Certain types of individuals, e.g., minorities, may have more barriers or perceived barriers to treatment utilization and may be more susceptible or perceive themselves to 
be more susceptible to developing an illness or having a worse prognosis for an illness (Bosworth, Oddone, \& Weinberger, 2006).

Enabling factors are factors that may facilitate or hinder an individual's ability to receive and follow through with treatment. These include community factors (e.g., health care facility within travel distance), social support factors (e.g., marital status), and personal factors (e.g., employment, health insurance, self-efficacy, co-occurring physical and/or mental health problems). Consistent with the Health Belief Model, these enabling factors would either increase the patient's perceived ability to utilize and engage in treatment and the lack of said factors would be perceived by the patients as barriers to obtaining treatment (Martin et al., 2010). A supportive partner, for example, can provide instrumental support, e.g., transportation to treatment and emotional support, e.g., help motivate the patient to adhere to tough treatment recommendations.

Need factors consist of both the individual's perception and treatment provider's perception of the severity of the symptoms experienced by the individual. Also consistent with the Andersen model, the Health Belief Model predicts that the greater the perceived symptom severity and/or severity of prognosis of their disease, the greater the intention to utilize health care services (Martin et al., 2010).

\section{Predictors of treatment attendance and adherence}

Anderson's (1995) treatment utilization model is well validated with many of its specified predictor variables having been found to be predictive of attendance in psychotherapy treatment. In general, psychotherapy research has found predisposing factors to be most consistently related to treatment attendance. Specifically, older adults, Caucasians, females and adults with more education were more likely to stay in psychotherapy treatment (Barrett, Chua, 
Crits-Christoph, Gibbons, \& Thompson, 2008; Reis \& Brown, 1999; Swift \& Greenberg, 2012; Wierzbicki \& Pekarik, 1993). Older adults may be less geographically mobile as they may not need to move around as much for work or school and older adults may have a stronger social support network, two factors which may increase the likelihood of remaining in treatment (Baekeland \& Lundwall, 1975). Caucasians may be more likely to remain in therapy as compared to minorities due to potentially differing expectations and needs of minority patients (Sue, 1977). Females may be more likely to attend and stay in psychotherapy as compared to males due to differences in socialized gender roles. Female gender roles include greater acceptability of expressing emotions and depending on others, especially for help with mental health concerns, while male gender roles emphasize emotional restrictiveness and independence, which is less likely to promote help seeking, especially for mental health concerns (Good, Dell, \& Mintz, 1989). Greater education may be associated with more willingness to attend to psychological wellbeing as well as greater verbal skills to comprehend the concepts presented in psychotherapy (Baum \& Felzer, 1964; Brill \& Storrow, 1960).

Enabling resources such as higher social support and higher socioeconomic status (SES) are associated with lower psychotherapy attrition (Barrett et al., 2008; Self, Oates, PinnockHamilton, \& Leach, 2005; Reis \& Brown, 1999; Wierzbicki \& Pekarik, 1993). The decreased attrition among individuals with higher SES can be explained by the crisis reactive nature of individuals who are economically disadvantaged. These individuals face so many life stressors on a daily basis that they only have time to attend to critical life stressors and mental health concerns many times do not reach the level of critical stressor as compared to other ongoing stressors in their lives (Lorion, 1974). Social support in the form of emotional support may enhance motivation for attending treatment and instrumental social support may assist in being 
able to attend treatment such as fulfilling transportation needs (Hays, Chauncy, \& Tobey, 1990; Rabkin, Williams, Neugebauer, Remien, \& Goetz, 1990).

In contrast to the predictions of the Anderson model, research with regard to need factors indicates that lower psychiatric symptomology and psychology distress is associated with lower psychotherapy attrition (Barrett et al., 2008; Derisley \& Reynolds, 2000; Pekarik, 1992). A degree of symptom severity and impairment may be needed to serve as a motivator to attend therapy however severe symptoms or disorders may impact the individual's capability to address their mental health concern and seek out psychotherapy services (Edelman \& Chambless, 1993; Holdsworth, Bowen, Brown, \& Howat, 2014).

Research into predictors of adherence to CBT instructions have been more limited and less systematic. Most research comes from single treatment studies of specific disorders (e.g., depression, anxiety, substance use). The most common predisposing factors that have been investigated were age, gender, and education. With the exception of one study which found older adults to be more adherent to homework assignments in CBT for panic disorder (Schmidt \& Woolaway-Bickel, 2000), CBT treatment studies for anxiety, depression, and substance use have found no relation between age and adherence (e.g., Bryant, Simons, \& Thase, 1999; Funk, Zvolensky, \& Schmidt, 2011; LeBeau, Davies, Culver, \& Craske, 2013). One CBT study of community CBT therapist's ratings of patient adherence found women to be more adherent to homework tasks (Helbig \& Fehm, 2004) however numerous CBT treatment studies of depression, anxiety, and substance use have not found any relation between gender and adherence (e.g., Decker et al., 2016; LeBeau et al., 2013; Sasso, Strunk, Braun, DeRubeis, \& Brotman, 2015). CBT studies generally did not find a relation between education and adherence (e.g., Gonzalez, Schmitz, \& DeLaune, 2006; Weck, Richtberg, Esch, Höfling, \& Stangier, 2013) 
except for one CBT treatment study of depression which found higher education level to be associated with greater homework adherence (Burns \& Spangler, 2000). Certain individual characteristics and certain types of people may be more likely to attend therapy, however among individuals in therapy, these characteristics may be less useful in predicting whether they will adhere to therapy recommendations. In addition to negatively impacting treatment attendance, limited enabling resources such as lack of social support, lack of self-efficacy, financial limitations have been hypothesized to negatively impact treatment adherence (Bosworth et al., 2006; Martin et al.,2010). CBT treatment studies typically do not assess for common enabling factors such as social support, socioeconomic status, and self-efficacy in relation to adherence (e.g., Fehm \& Mrose, 2008; Rees, McEvoy, \& Nathan, 2005; Sachsenweger, Fletcher, \& Clarke, 2015; Willner-Reid et al., 2016). Enabling factors with respect to adherence thus represents a large gap in the literature that needs to be addressed. Need factors, specifically, pre-treatment symptom severity, have been investigated in CBT treatments for depression, anxiety, and substance use which generally show no relation between initial symptom severity and level of adherence during treatment (e.g., Burns \& Nolen-Hoeksema, 1991; Edelman \& Chambless, 1995; Gonzalez et al., 2006; Rees et al., 2005). Similar to predisposing characteristics, need characteristics may be useful in predicting whether individuals attend therapy, however among those who do attend therapy, symptom severity may not be as useful in predicting whether these individuals will adhere to therapy recommendations.

Researchers have utilized the Anderson (1995) model to predict utilization of a number of different types of treatment. These include complementary and alternative medicine treatment (Brown, Barner, Bohman, \& Richards, 2009), Human Immunodeficiency Virus treatment (Anthony et al., 2007), anxiety disorder treatment (Keyes et al., 2008), panic disorder treatment 
(Goodwin \& Andersen, 2002), mood disorder treatment (Keyes et al., 2008), alcohol use disorder treatment (Zemore, Mulia, Ye, Borges, \& Greenfield, 2009), substance use disorder treatment (Keyes et al., 2008), depression and substance use disorder treatment (Tate et al., 2011), and substance use and PTSD treatment (Cui et al., 2016).

There is limited research regarding predisposing, enabling, and need factors associated with CBT-I treatment attendance and adherence. With respect to predisposing factors, females were more likely than males to remain in Dashevsky and Kramer's (1997) treatment study investigating the effectiveness of combined CBT-I and pharmacotherapy treatment for insomnia symptoms among individuals with psychiatric illnesses. To be included, participants must have failed to respond to psychotropic medications for insomnia and have one or more psychiatric diagnoses. A group cognitive behavioral treatment for insomnia study found older participants to be more adherent to a consistent wake time (Vincent, Lewycky, \& Finnegan, 2008). The study utilized a community sample and only excluded individuals with shift work, schizophrenia, bipolar disorder, and/or head injuries however the analyses predicting adherence was only conducted on a subset of the sample, i.e., those who have completed the study (Vincent et al., 2008).

Several studies have investigated enabling factors associated with CBT-I treatment utilization. Individuals with insomnia and no co-occurring physical or mental health problem were more likely to complete CBT-I treatment for insomnia as compared to individuals with mental or physical health comorbidities in Dashevsky and Kramer's (1997) study of combined CBT-I and pharmacotherapy treatment for insomnia. Vincent and Hameed (2003) conducted a study investigating adherence to CBT-I group treatment which excluded individuals who showed symptoms of other sleep disorders (e.g., sleep apnea), had traumatic brain injuries, had bipolar 
disorder, had schizophrenia, or had medical conditions (e.g., pain). They found that individuals without a comorbid dysthymia disorder received higher ratings of adherence from therapists during treatment as compared to individuals with a comorbid dysthymia disorder. Lower cooccurring depressive symptom severity was also found to be associated with greater adherence to a fixed wake time as well as greater adherence to a set time to be spent in bed in the group CBT-I study conducted by Manber and colleagues (2011). Although the sample used was a community sample which did not exclude co-occurring psychiatric or medical disorders, the adherence analyses was only conducted on the subset sample of treatment completers. A study conducted by Bouchard and colleagues (2003) investigated the relation between self-efficacy and adherence to CBT-I treatment for insomnia and found that having higher levels of self-efficacy was associated with increased adherence to CBT-I treatment components. Their treatment study had excluded individuals with sleep apnea, with restless legs syndrome, using sleep medications, in psychotherapy, and with co-occurring mental and/or physical health conditions.

Lastly, several need factors relating to sleep problem severity have been found to be associated with CBT-I treatment utilization. Having lower fatigue during the baseline time period was associated with a greater likelihood of completing Dashevsk and Kramer's (1997) combined CBT-I and pharmacotherapy treatment study. Morgan and colleagues (2003) conducted a study investigating predictors of attrition in CBT-I treatment with a sample of individuals using prescription sleep aids. Their study found that individuals with more severe sleep disturbances at treatment entry were more likely to remain in CBT-I treatment. A study conducted by Ong and colleagues (2008) found that individuals with more total sleep time at the start of treatment were more likely to complete CBT-I treatment. The inclusion and exclusion criteria for their participant sample was not reported. These studies suggest that more severe 
insomnia symptoms (e.g., sleep disturbances) at treatment entry may be associated with a greater perception of need for insomnia treatment and facilitate treatment completion. However, more severe insomnia symptoms (e.g., greater daytime fatigue, less total sleep time) may also act as enabling factors that hinder an individual's ability to engage in treatment.

\section{Statement of the problem and hypotheses}

A model of treatment utilization proposed by Andersen (1995) identifies a number of variables to be predictive of treatment utilization which are conceptualized into three categories, predisposing, enabling, and need factors. Generally in psychotherapy research, predisposing factors of age, gender, ethnicity, and education, enabling factors of social support and socioeconomic status, and need factors of symptom severity and distress have been found to be associated with treatment utilization. With respect to CBT-I treatment research, the predisposing factor of gender, the enabling factor of co-occurring physical or mental health problems, and the need factor of insomnia symptom severity have been found to be associated with CBT-I treatment attendance. Further, the predisposing factor of age, enabling factors of depression, motivation, and self-efficacy, and the need factor of fatigue were found to be associated with CBT-I treatment adherence. However, to date, all the insomnia treatment studies that have investigated predictors of treatment attendance and treatment adherence have used strict inclusion and exclusion criteria and/or conducted adherence analyses only with the treatment completer subset of the sample, which limit the generalizability of the findings to community populations with insomnia. It is also unknown if factors that were found to be unrelated to treatment attendance utilizing restrictive homogeneous samples or factors unrelated to adherence utilizing only treatment completers will be predictive of treatment attendance and/or adherence in a more heterogeneous sample of treatment seekers that more closely resembles community 
populations with insomnia. Additionally, CBT-I treatment attendance has been defined multiple ways (e.g., attend all sessions, Eddinger et al., 2001; attend a certain number of sessions, Ong et al., 2008; number of sessions attended, Morin et al., 1999) and it is unknown if factors found to be predictive of attendance defined as having attended all sessions will still be predictive when operationalized as having attended a minimal number of sessions or operationalized as a count number of sessions attended.

The proposed study investigated a variety of predisposing, enabling, and need variables as predictors of CBT-I treatment attendance and adherence in a primary care treatment setting. The study examined predictors of both attendance and adherence utilizing a well validated model of treatment utilization (Andersen, 1995) as a conceptual framework for understanding and organizing predictor variables. Some researchers have conceptualized attendance as another measure of adherence to therapist recommendations (e.g., Taft, Murphy, King, Musser, \& DeDeyn, 2003) however for the purposes of this study, attendance and adherence are investigated as separate constructs consistent with much of the literature on CBT-I treatment (e.g., Matthews, Arnedt, McCarthy, Cuddihy, \& Aloia, 2013). The following predisposing, enabling, and need factors are hypothesized to be associated with treatment attendance based on previous psychotherapy attendance research and CBT-I attendance research. Predisposing factors of being older, female, white, and having more education are predicted to be associated with greater treatment attendance. Enabling factors of having fewer co-occurring mental and/or physical health problems, having greater social support, and being employed are predicted to be associated with greater treatment attendance. Need factor of greater insomnia symptomology is predicted to be associated with greater treatment attendance. There is limited research regarding consistent predictors of treatment adherence in psychotherapy treatments in general and the 
CBT-I adherence research is also limited and have typically used a treatment completion sample which hinders the interpretation of their findings. Consequently, exploratory analyses investigated predisposing, enabling, and need factors as they relate to treatment adherence however no hypotheses are made regarding these relations.

This study has unique strengths which address several limitations in the present literature. The majority of participants in this study were referred by a health care provider with only one patient having been self-referred to the clinic. As many individuals first seek treatment for insomnia from a health care provider (Leger \& Poursain, 2005), the recruitment process utilized in the study supports the validity of the findings. The generalizability of the findings is further supported through the use of minimal inclusion and exclusion criteria for participant recruitment and statistical analyses. The present study examined adherence as two separate continuous variables, variation in time that the participant got into bed with the intention of sleeping (bed time) and variation in time that the participant woke up and got out of bed with the intention of no longer sleeping (wake time). Since there is no established definition of attendance in the field of insomnia treatment research, the present study examined attendance as two categorical variables, attend three or more sessions vs attend two or fewer sessions and attend all recommended sessions vs did not attend all recommended sessions as well as a continuous variable of number of sessions attended among individuals who did not attend all recommended sessions. The distinction between three or more sessions vs two or fewer sessions was made because the core components of CBT-I, i.e., sleep restriction, stimulus control, and sleep hygiene, are introduced during the first three sessions (Perlis et al., 2006).

\section{Method}




\section{Participants and procedures}

Participants were 156 outpatients from the Clark K. Sleeth Family Medicine Center Insomnia Clinic in Morgantown, West Virginia. Participants were recruited between 2009 and 2016. Morgantown is located in Monongalia County, which is comprised of both urban and rural communities with residents from diverse socioeconomic backgrounds. The patients seen at the clinic come from Monongalia County as well as other surrounding counties as the present study did not have a distance exclusion criterion. Participants were individuals referred by their general practitioners if they expressed sleep problems and were interested in receiving psychotherapy for insomnia. Patients were not charged any fees to be seen at the Insomnia Clinic. Individuals were screened for eligibility to receive CBT-I treatment during a one-hour intake interview.

Participants were not compensated for attending therapy sessions, completing questionnaires, or completing home assignments. Additionally, participants were not reimbursed for cost of travel (e.g., gas for miles driven, bus tokens). All study procedures were approved by West Virginia University’s Institutional Review Board.

All 156 participants had attended at least the intake interview session at the Insomnia Clinic. The data for the present study consist of information the patients provided during routine clinical care at the Insomnia Clinic. Additionally, ethnicity, gender, type of insurance, health conditions, and progress notes were obtained through chart reviews.

An effort was made to determine how many people were referred but did not attend even one session. During the recruitment time period, a subset of individuals referred to the clinic did not follow through with the referral and were thus not recruited for this study. Data on follow through with referral were available for the June 2015 to June 206 timeframe during which time 49 individuals were referred to the clinic of whom nine did not attend any sessions. 
Inclusion criteria were: a) at least 18 years of age and b) current diagnosis of primary or secondary insomnia based on DSM-IV-TR (American Psychiatric Association, 2000) or DSM-V (American Psychiatric Association, 2013) criteria. Participants were excluded if they a) had a cooccurring psychiatric or medical condition that would make participation unfeasible, or b) had a co-occurring sleep-wake disorder that was not being adequately managed. Eligible participants who agreed to participate in the treatment provided written informed consent to receive CBT-I treatment in the first session. The final sample consisted of 108 participants. Reasons for exclusion are presented in Figure 1.

Insomnia diagnoses. The diagnosis of insomnia disorder was made using information obtained at intake from a semi-structured interview as well as information obtained from a review of the participant's medical charts and from the participant's self-report assessment measures. Diagnosis of insomnia for participants was based on either DSM-IV-TR or DSM-5, which was published in 2013. Diagnostic criteria for Primary Insomnia based on the DSM-IVTR are as follows: for one month, the individual has difficulty falling or staying asleep or their sleep is nonrestorative and these symptoms cause significant distress or impairment. The DSM-5 criteria for Insomnia Disorder are more specific, requiring sleep problems to be present for at least three nights per week for at least three months despite having sufficient opportunity to sleep. Sleep problems are defined as difficulty falling asleep, staying asleep, and/or waking earlier than intended and having difficulty falling back asleep and these sleep problems must cause significant distress or impairment.

\section{Cognitive Behavioral Therapy for Insomnia}

CBT-I provided in this study was based on Perlis and colleagues' (2006) Cognitive Behavioral Treatment of Insomnia manual. In the current study, CBT-I was comprised of four 
components from Perlis and colleagues' (2006) manual, which are stimulus control, sleep restriction, sleep hygiene, and cognitive restructuring. Additionally, the CBT-I used in this study includes an added component of progressive muscle relaxation that was not part of the manual. CBT-I consists of at least six 60-minute sessions provided approximately once every week to every two weeks depending on clinic availabilities and the availabilities of the participants. Depending on mitigating factors such as severity of the participant's insomnia, whether participants wanted assistance in titrating off sleep aids, and/or presence of co-occurring physical or mental health problems, additional therapy sessions were provided as needed. Treatment sessions were heavily structured and provided in a didactic format. Sleep diaries would be provided at the end of every treatment session and reviewed at the beginning of every treatment session. Participants were tasked with providing sleep diary data for every day during the treatment period. If a participant wished to titrate off their sleep aid, the therapist worked with the participant and the participant's primary care provider to create an individualized titration plan and incorporate it into their treatment.

The majority of participants received individual CBT-I treatment (individual CBT-I = 101 participants, group CBT-I = 7 participants). Group CBT-I differed from individual CBT-I in that individuals would meet with a therapist one on one for their first intake session and for the rest of their therapy sessions, they would meet for a few minutes with their therapist before the group treatment started so that their therapist can review their sleep diary with them and adjust their sleep prescription after which the individual would meet with their therapist in a group setting with other patients.

CBT-I was implemented by graduate student trainees enrolled in an APA-accredited clinical psychology doctoral training program. The Insomnia Clinic team consisted of a licensed 
clinical psychologist who is certified in behavioral sleep medicine and a mid-level supervisor who was an advanced graduate student, a graduate student intern, or a postdoctoral fellow, and two to three first- or second-year graduate students. All therapies were provided by first- or second-year graduate students who were trained and supervised by the licensed psychologist and the mid-level supervisor. Supervisors observed the first- and second-year graduate students either in person or via live stream from a monitor. Supervision was provided in group format to trainees after live observation of therapy sessions conducted by trainees.

Session 1-Intake. Prior to the intake session, the therapist reviewed the participant's medical charts. During the session, the therapist conducted an unstructured interview with the participant. Additionally, the participant would complete several self-report questionnaires at the beginning or end of the session. All information obtained was integrated to determine whether the participant met criteria for insomnia. If the participant failed to meet criteria, they were referred to primary care or a sleep clinic. If the participant met criteria for insomnia but had a cooccurring medical, psychiatric, or sleep-wake disorder that would make participation unfeasible, the participant was advised to seek treatment for said disorders and return to clinic once their other disorders were under control. At the end of the session, the participant would be provided with their first sleep diary to track their sleep.

Session 2-CBT model. The therapist provided didactics on the Speilman model of how insomnia develops. Specifically, the therapist explained how predisposing, precipitating, and perpetuating factors function to trigger and maintain one's insomnia as well as the rationale for enacting stimulus control and following a sleep prescription. The therapist then provided the patient with instructions to enact stimulus control (i.e., do not engage in any activities in the bedroom except for sleep and sex, get out of bed after 15 minutes of being awake) and an 
individualized sleep prescription in the form of sleep restriction or sleep compression. Sleep restriction consisted of restricting the participant's time allotted to spend in bed to the average amount of time they spend sleeping each night. Each week, if the participant's sleep efficiency (total sleep time/time in bed) was $85 \%$ or greater, they would gain an additional 15 minutes of allotted time in bed. If the sleep efficiency was less than $80 \%$, the participant's time allotted to spend in bed may be further restricted if early in treatment or in most cases, left the same. Sleep compression consisted of restricting the participant's time allotted to spend in bed by one fifth of the difference between the total time that they spend in bed and their total sleep time until their sleep efficiency is above $80 \%$ during the week. Then, if their sleep efficiency is above $85 \%$ during the week, they would gain an additional 15 minutes of allotted time in bed and if their sleep efficiency fell below $80 \%$ during the week, they would lose an additional 15 minutes. The sleep prescription decisions were based on the individual's sleep diary data collected between session one and two. In each subsequent session, the sleep prescription would be adjusted as necessary.

Session 3-Sleep hygiene. The therapist provided the participant with didactics on sleep hygiene and a list of 14 sleep hygiene instructions (e.g., sleep only as much as you need, get up at the same time each day, exercise regularly, etc.; Perlis et al., 2006). The therapist went through the list of instructions, provided the rationale for following each of them, and advised the participant to follow all 14 instructions. The amount of time spent discussing each instruction depended on the participant's interest and the relevance of the instruction to the participant.

Session 4-Progressive muscle relaxation. The therapist provided the rationale for doing relaxation training and demonstrated how to do progressive muscle relaxation. The participant practiced the technique and was then provided feedback from the therapist. Participants were 
instructed to practice doing progressive muscle relaxation at least once a day.

Session 5-Cognitive restructuring. The therapist worked with the participant to identify and challenge maladaptive and inaccurate beliefs regarding the consequences of getting a poor night's sleep, with the goal of decreasing the participant's anxiety and increasing the participant's adherence to the sleep prescription.

Session 6-Relapse prevention. The therapist reviewed with the patient the conceptual model of how insomnia begins and the patient's progress during treatment. The therapist provided didactics on how to continue to self-monitor and adjust one's sleep schedule. The therapist also provided information on what to do to prevent a relapse from occurring, how to determine if a relapse has occurred, and what to do in the event of a relapse.

Additional sessions may take place between the cognitive restructuring session and the relapse prevention session if sufficient treatment gains have not been made by the participant and/or if judged beneficial by the therapist. These additional sessions may include additional sleep monitoring and modifications to the sleep prescription, teaching additional relaxation techniques, and teaching skills to better manage other sleep-wake disorders (e.g., Imagery Rehearsal Therapy skills to manage Nightmare Disorder). For additional information on the treatment protocol, see Perlis and colleagues (2006). If the participant had failed to make significant gains by the end of treatment, the participant was referred for additional evaluation, as appropriate, such as a sleep study or medical evaluation.

\section{Measures}

Demographic variables were assessed at intake using a biological questionnaire (Appendix H) and through chart review. Sleep diaries were completed throughout the treatment period including at intake and end of treatment. All other measures were administered at intake 
and treatment completion. Missing information was obtained through chart review if possible. Mean imputation of missing items on the sleep, depression, and anxiety measures was conducted if the number of items missing was $20 \%$ or less. If the number of missing items was greater than $20 \%$, the measure would be excluded from analyses.

Demographic Information. Demographic data consisted of age, gender (coded $1=$ male, $0=$ female), ethnicity (coded $1=$ non-Hispanic white, $0=$ other $)$, level of education $($ coded $1=$ college or more, $0=$ high school or less), employment status $($ coded $1=$ working, $2=$ not working, $3=$ retired, $4=$ disabled $)$, insurance status $($ coded $0=$ private, $1=$ Medicare, $2=$ Medicaid $)$, marital status $(0=$ not married, $1=$ married $)$, number of co-occurring physical health problems (Appendix I), and name of prescription sleep medications taken by participants. Age, education level, employment status, and marital status were obtained from the biological questionnaire. Age and marital status for six individuals, education level for four individuals, and employment status for five individuals were obtained through chart review. Gender, ethnicity, insurance status and name of prescription sleep medication were obtained through chart review for every participant. Number of health problems was obtained from the Medical History Information Form (Appendix I) based on how many health conditions the participants endorsed. Twelve participants had completed the information form and the number of health conditions for the remaining 96 participants was obtained through chart review based on how many of the health conditions listed on the information form was listed as a diagnosis in the participant's medical records.

Epworth Sleepiness Scale (ESS; Appendix A; Johns, 1991). The ESS is a self-report measure of average level of sleepiness during the day over the last one week period. The ESS is comprised of eight items describing eight different frequently encountered situations. 
Participants would rate their likelihood of falling asleep in each situation on a scale of $0=$ would never doze to $4=$ high chance of dozing. The ESS has demonstrated a test-retest reliability of .82 over a five month period and a Cronbach's alpha of .88 (Johns, 1992). Scores of 10 or greater have been used as an indication of clinically significant levels of daytime sleepiness (Buysse et al., 2008). In the current study, the ESS was used as a continuous measure of severity of daytime sleepiness. The Cronbach's alpha for the ESS in this study was .88.

Insomnia Severity Index (ISI; Appendix B; Bastien, Vallières, \& Morin, 2001). The ISI is a brief self-report assessment of severity of insomnia symptoms. The ISI consists of seven items assessing insomnia symptom severity and impact on life functioning on a scale of $0=$ none/not at all to $4=$ very/very much. Cronbach's alphas of .74 to .91 have been found for the ISI (Bastien et al., 2001; Morin, Belleville, Bélanger, \& Ivers, 2011). For detecting insomnia, a score of 10 or higher was recommended as the cutoff in community samples and a score of 11 or higher was recommended as the cutoff in clinical samples (Morin et al., 2011).

Recommendations for interpreting scores as an indication of insomnia severity are as follows: 0 $-7=$ no insomnia, $8-14=$ subthreshold insomnia, $15-21=$ moderate insomnia, and $21-28=$ severe insomnia (Smith, \& Wegener, 2003). The ISI was used as a continuous measure of severity of insomnia symptoms. Mean imputation was used to impute missing items on the ISI for two individuals. The Cronbach's alpha for the ISI in this study was .75.

Pittsburgh Sleep Quality Index (PSQI; Appendix C; Buysse, Reynolds, Monk, Berman, \& Kupfer, 1989). The PSQI is a self-report measure of sleep quality and sleep disturbance over the past one month period. The PSQI consists of 19 items rated on a $0=$ not during the past month to $3=$ three or more times a week scale. The 19 items are used to calculate seven component scores (sleep quality, sleep latency, sleep duration, habitual sleep efficiency, sleep 
disturbances, use of sleeping medication, and daytime dysfunction) and a global rating of sleep quality ranging from 0 to 21 . The PSQI has demonstrated a Cronbach's alpha of .83 and a testretest reliability of .85 over a 28 day period (Buysse et al., 1989). A global rating score five or greater indicates clinically significant poor sleep quality indicative of the presence of a sleep disorder (Buysse et al., 1989). The PSQI was used as a continuous measure of severity of sleep disturbances. Mean imputation was used to impute missing items on the PSQI for 21 individuals. The Cronbach's alpha for the PSQI in this study was .53.

Beck Anxiety Inventory (BAI; Beck, Epstein, Brown, \& Steer, 1988). The BAI is a selfreport measure of anxiety symptom severity during the past week. The BAI consists of 21 items of anxiety symptoms rated on a scale of $0=$ not at all to $3=$ severely, could barely stand it, based on how much each symptom bothered the individual. A test-retest reliability of .75 over a one week period and a Cronbach's alpha of .92 have been found for the BAI (Beck et al., 1988). Scores between 10 and 18 suggests mild anxiety and scores of 19 and above suggest moderate anxiety (Kabacoff, Segal, Hersen, \& Van Hasselt, 1997). The BAI was used as a continuous indicator of anxiety symptom severity. Mean imputation was used to impute missing items on the BAI for five individuals. The Cronbach's alpha for the BAI in this study was .91.

Center for Epidemiologic Studies Depression - Revised (CESD-R; Appendix D; Eaton, Smith, Ybarra, Muntaner, \& Tien, 2004). The CESD-R is a self-report measure of level of depressive symptoms. The assessment consists of 20 items describing depressive symptoms that are rated for how often they were experienced during the past week on a scale of 0 (not at all or less than 1 day) to 3 . The last two items of the scale, "5-7 days" and "nearly every day for 2 weeks," were both scored as a 3 based on scoring procedures described by Van Dam and Earleywine (2011). A Cronbach's alpha of .93 has been found for the CESD-R (Van Dam \& 
Earleywine, 2011). Scores of 16 or greater indicate probable depression (Eaton et al., 2004). The CESD-R was used as a continuous measure of depressive symptom severity. Mean imputation was used to impute missing items on the CESD-R for 17 individuals. The Cronbach's alpha for the CESD-R in this study was .92 .

Sleep diaries (Appendix G). Diaries were completed by participants at every session following intake. Sleep diaries were reviewed with participants at the beginning of every session and used to revise the participant's sleep prescription as needed. Sleep diaries provided the following sleep parameter data: fatigue level, frequency and duration of naps, usage of medications and/or substances, bed time, wake time, desired wake time, sleep onset latency, wake after sleep onset, frequency of nocturnal awakenings, terminal wakeful time, total sleep time, time in bed, and sleep efficiency. The accuracy of sleep diaries in measuring sleep parameter data has been found to be similar to that of actigraphy (Vallières \& Morin, 2003). There was greater discrepancy between polysomnography and sleep diary on sleep onset latency as compared to between polysomnography and actigraphy however there were no significant discrepancies between polysomnography and sleep diary or between polysomnography and actigraphy on total sleep time, sleep efficiency, and time in bed (Vallières \& Morin, 2003). The diary(s) completed by participants between session one and session two were used to assess baseline sleep parameters, after which the rationale and recommendation for adhering to a consistent bed and wake time was provided in session two. Forty-four individuals had completed one or more sleep diaries for the weeks in which they had a recommended bed time and wake time, i.e., weeks following session two (nine individuals had one diary, six individuals had two diaries, two individuals had three diaries, eleven individuals had four diaries, twelve individuals had five diaries, two individuals had six diaries, three individuals had seven diaries, and one 
individual had nine diaries). To maintain consistency across participants, the diary(s) completed based on the first prescribed bed time and wake time, i.e., diary(s) completed for week(s) between session two and session three, was used as the measure of adherence in this study. All sleep diaries were entered by research assistants. Variation in bed times consisted of standard deviation in times recorded in column A of the sleep diary, "Time you went to bed and turned out lights," and variation in wake times consisted of standard deviation in times recorded in column D of the sleep diary, "Time you woke up this morning for the last time."

\section{Analyses}

Predisposing, enabling, and need factors were used to predict treatment attendance and treatment adherence. Treatment attendance consisted of two dichotomous outcome variables. The first variable is coded $1=$ attended at least three treatment sessions and $0=$ attended fewer than three treatment sessions. The second variable is coded $1=$ attended all recommended treatment sessions including relapse prevention and $0=$ did not attend all recommended treatment sessions. Participants were coded as having attended all recommended treatment sessions if they attended the relapse prevention session since this session was always delivered as the last session. Secondary analysis of attendance was conducted to predict number of sessions attended among individuals who did not attend all recommended sessions. Treatment adherence consisted of two outcome variables: a continuous variable of variation in bed time and a continuous variable of variation in wake time, both measured in minutes. Variation in bed times and wake times have been used as measures of adherence in multiple studies (e.g., Riedel \& Lichstein, 2001; Vincent \& Hameed, 2003).

Predisposing predictors were comprised of age, gender, ethnicity, and education level. Enabling predictors were comprised of employment status, number of physical health problems, 
insurance status, marital status, BAI, and CESD-R. Need predictors were comprised of PSQI, ESS, ISI. All predictor measures used in the analyses were collected at baseline.

Separate logistic regressions were used to determine whether predictor variables were associated with whether individuals attended three or more sessions versus two or fewer sessions as well as whether individuals attended all recommended sessions versus did not attend all recommended sessions. In logistic regressions, zero was used as the reference group for categorical variables. Separate linear regressions were used to examine the relation between predictor variables and number of sessions attended, variations in bed times, and variations in wake times.

Separate multiple logistic regressions and multiple linear regressions were conducted using predictors that were significant at the univariate level. Predisposing predictors that were significant at the univariate level were entered in the multiple regression models in step one and enabling predictors that were significant at the univariate level were entered into step two of the multiple regression models to see if significant enabling predictors added any additional predictive utility over and above significant predisposing predictors. Additionally, multiple regression analyses were conducted where predisposing predictors that were significant at the univariate level were entered into step one and need predictors that were significant at the univariate level were entered into step two of the multiple regression models to see if need predictors added any additional predictive utility over and above predisposing predictors. Traditionally, it has been recommended to have 10 events per predictor in logistic regression (Peduzzi, Concato, Kemper, Holford, \& Feinstein, 1996; Vittinghoff \& McCulloch, 2007). For the attending all sessions variable, there were only 26 events in the smallest group (attended all recommended sessions group) and thus there was only sufficient power to investigate two 
predictor variables in a multiple logistic regression. Consequently, predictors for this variable were only analyzed at the univariate level.

\section{Results}

\section{Sample characteristics}

The final sample was comprised of 108 participants. Participants were primarily female $(71.3 \%)$ middle aged $(\mathrm{M}=50.5, \mathrm{SD}=14.6)$ Caucasian $(92.6 \%)$ adults. Thirty three participants were using prescription sleep medications at intake (one used Clonazepam [Klonopin], one used Doxepin [Zonalon], one used Eszopiclone [Lunesta], six used Temazepam [Restoril], one used Zaleplon [Sonata], and 23 used Zolpidem [Ambien]). Additional demographic information and means and standard deviations for the variables of interest are presented in Table 1.

Participants completed on average 3.37 sessions $(S D=2.74)$ and the maximum number of sessions a participant had completed was 11 sessions. Participants completed on average 2.22 sleep diaries $(S D=2.66)$, indicating that participants completed their assigned sleep dairies 93.67\% of the time (participants were not given a sleep diary to complete and bring to the first intake session). The majority of participants did not attend three or more sessions (50 participants attended three or more sessions) or complete treatment (26 participants attended all recommended treatment sessions). On average, participants deviated from a consistent bed time by 27 minutes $(S D=29.00)$ and deviated from a consistent wake time by 40 minutes $(S D=$ 25.90). The majority of participants, 101 participants, received individual CBT-I while seven participants received group CBT-I treatment. Participants receiving individual CBT-I did not differ from participants receiving group CBT-I on any outcome measures (See Table 2). Multiple imputation was used to deal with missing data in multiple linear regression and multiple logistic regression analyses. All predictors of interest were normally distributed and all assumptions of 
multiple regression were met for the analyses conducted in this study. The relations among continuous predictor variables are presented in Table 3.

\section{Predictors of attending three or more sessions}

Bivariate logistic regression models were used to investigate the relation between each predictor variable and attending three or more sessions separately.

Predisposing factors. Age was significantly associated with attendance, $N=108, b=$ 0.04 , Wald $\chi^{2}(1)=7.43, p<.01$, with individuals attending three or more sessions being older on average (mean age $=54.72, \mathrm{SD}=15.38$ ) as compared to individuals attending two or fewer sessions (mean age $=46.78, \mathrm{SD}=12.99$ ). Education, ethnicity, and gender were not associated with whether individuals attended three or more sessions (See Table 4).

Enabling factors. Anxiety symptoms were significantly associated with attendance, $N=$ $103, b=-0.06$, Wald $\chi^{2}(1)=7.53, p<.01$, with individuals attending three or more sessions having lower levels of anxiety symptoms (mean BAI score $=10.21, \mathrm{SD}=9.33$ ) on average as compared to individuals attending two or fewer sessions (mean BAI score $=16.36, \mathrm{SD}=11.32$ ). Additionally, depressive symptoms were significantly associated with attendance, $N=107, b=$ 0.04 , Wald $\chi^{2}(1)=5.95, p=.01$, with individuals attending three or more sessions having less depressive symptoms on average (mean CESD-R score $=15.92, \mathrm{SD}=11.89$ ) as compared to individuals attending two or fewer sessions (mean CESD-R score $=22.16, \mathrm{SD}=13.15$ ). Employment status, number of co-occurring physical health problems insurance status, and marital status were not associated with whether individuals attended three or more sessions (See Table 4).

Need factors. No need factors were associated with whether individuals attended three or more sessions (See Table 4). 
Combined model. A multiple logistic regression model was conducted where age was entered into step one and anxiety and depressive symptoms were entered into step two of the model. Multiple imputation was used to impute values for missing data. Twenty imputations were run to impute six missing observations. In step one of the model, age was significantly associated with attendance, $b=0.04$, Wald $\chi^{2}(1)=7.43, p<.01$, with the log likelihood of the model being -70.41. In step two of the model, age remained significant, $b=0.04, p=.02$, as did anxiety symptoms, $b=-0.07, p=.0497$, however depressive symptoms were not significant, $b=$ $0.01, p=.62$, with the log likelihood of the model decreasing to -66.66 (see Table 5).

\section{Predictors of attending all recommended sessions}

Bivariate logistic regression models were used to investigate the relation between each predictor variable and attending all recommended sessions separately.

Predisposing factors. Age was significantly associated with attendance, $N=108, b=$ 0.06 , Wald $\chi^{2}(1)=10.51, p<.01$, with individuals who attended all recommended sessions being older on average (mean age $=59.27, \mathrm{SD}=13.61$ ) as compared to individuals who did not attend all recommended sessions (mean age $=47.66, \mathrm{SD}=13.88$ ). Education, ethnicity, and gender were not associated with whether individuals attended all recommended sessions (see Table 6). Results for the ethnicity predictor should be interpreted with caution due to the smallest cell containing only five individuals.

Enabling factors. Anxiety symptoms were significantly associated with attendance, $N=$ $103, b=-0.07$, Wald $\chi^{2}(1)=5.15, p=.02$, with individuals who attended all recommended sessions having less anxiety symptoms on average (mean BAI score $=9.06, \mathrm{SD}=7.54$ ) as compared to individuals who did not attend all recommended sessions (mean BAI score $=14.92$, $\mathrm{SD}=11.38$ ). Depressive symptoms were also significantly associated with attendance, $N=107$, 
$b=-0.07$, Wald $\chi^{2}(1)=7.97, p<.01$, with individuals who attended all recommended sessions having less depressive symptoms on average (mean CESD-R $=12.77, \mathrm{SD}=10.11$ ) as compared to individuals who did not attend all recommended sessions (mean CESD-R score $=21.40, \mathrm{SD}=$ 13.07). Employment status, number of co-occurring physical health problems, insurance status, and marital status were not associated with whether individuals attended all recommended sessions (see Table 6). Results for the employment predictor should be interpreted with caution due to the second smallest cell containing two individuals and the smallest cell containing zero individuals. Additionally, results for the insurance predictor should also be interpreted with caution due to the second smallest cell containing six individuals and the smallest cell containing zero individuals.

Need factors. Insomnia symptoms were significantly associated with attendance, $N=$ $105, b=-0.12$, Wald $\chi^{2}(1)=5.37, p=.02$, with individuals who attended all recommended sessions having lower levels of insomnia symptoms on average (mean ISI score $=17.85, \mathrm{SD}=$ 4.79) as compared to individuals who did not attend all recommended sessions (mean ISI score = 20.30, SD = 4.35). No other need factors were associated with whether individuals attended all recommended sessions (see Table 6).

Secondary analysis predicting number of sessions attended. Bivariate linear regression models were used to investigate the relation between each predictor variable and number of sessions attended separately among individuals who did not attend all recommended sessions (Table 7). Among these individuals, only age was significantly associated with number of sessions attended, $t(80)=2.25, p=.03$, with older individuals having attended more sessions.

\section{Predictors of adherence to consistent bed time}

Bivariate linear regression models were used to investigate the relation between each 
predictor variable and consistency of bed times separately.

Predisposing factors. Age was significantly associated with standard deviation of bed times, $t(42)=-2.56, p=.01$. Higher age was associated with greater consistency in going to bed at the same time every day (i.e., lower standard deviation of bed times). Education, ethnicity, and gender were not associated with consistency in bed times (see Table 8).

Enabling factors and need factors. No enabling or need factors were associated with consistency in bed times (see Table 8).

\section{Predictors of adherence to consistent wake time}

Bivariate linear regression models were used to investigate the relation between each predictor variable and consistency of wake times separately.

Predisposing factors. Age was significantly associated with standard deviation of wake times, $t(42)=-2.21, p=.03$. Older individuals more consistently woke up at the same time every day. Education, ethnicity, and gender were not associated with consistency in wake times (see Table 9).

Enabling factors. Depressive symptoms were significantly associated with standard deviation of wake times, $t(42)=2.06, p=.045$. Higher depressive symptoms among individuals were associated with lower levels of consistency in waking up at the same time every day. Anxiety symptoms, employment status, number of co-occurring physical health problems, insurance status, and marital status were not associated with consistency in wake times (see Table 9).

Need factors. No need factors were associated with consistency in wake times (see Table 9).

Combined model. A multiple linear regression model was conducted where age was 
entered into step one and depressive symptoms were entered into step two of the model. In step one of the model, age was significantly associated with standard deviation in wake time, $t(42)=$ $2.21, p=.03$, with the $\mathrm{R}$-square for the model being .10 . In step two of the model, age and depressive symptoms were not significant, $t(41)=-1.61, p=.12 ; t(41)=1.41, p=.16$; respectively, with the r-square for the model increasing to .15 (see Table 10).

\section{Discussion}

The present study investigated whether the following predisposing factors (age, gender, ethnicity, education level), enabling factors (employment status, insurance status, marital status, anxiety symptoms, and depressive symptoms), and need factors (sleep problem severity) were associated with individuals' attendance of Cognitive Behavioural Therapy for Insomnia (CBT-I) and adherence to treatment recommendations of the therapists (i.e., adhering to a consistent bed time and wake time). Individuals who met inclusion criteria attended an average of 3.4 treatment sessions and 26 individuals out of the 108 individuals in this study completed all recommended treatment sessions. During the first week that participants were recommended to adhere to a consistent sleep and wake time (i.e., going to bed at the same time every day and getting out of bed at the same time every day), individuals deviated from a consistent bed time by 27 minutes and deviated from a consistent wake time by 40 minutes. The number of individuals who completed treatment was lower than what has been commonly found in the literature for CBT-I treatment, which typically indicates a completion rate of $50 \%$ to $66 \%$ among studies recruiting a community sample using relaxed inclusion and exclusion criteria (Espie et al., 2008; Espie et al., 2007; Morgan et al., 2003). The number of minutes that individuals deviated from a consistent bed and wake time was similar to what has been reported in previous studies (e.g., 28 minutes, Riedel \& Lichstein, 2001). 
Consistent with a prior study of CBT-I treatment (Vincent et al., 2008), age was associated with treatment attendance in the present study with older adults being more likely to attend three or more treatment sessions as well as to complete CBT-I treatment. Older individuals were also more consistent in going to bed at the same time every night as well as getting out of bed at the same time every morning. CBT-I treatment is heavily structured and didactic in nature and younger patients may prefer to have a more active role in their treatment (Bosworth et al., 2006), which may explain why younger adults were less likely to attend CBT-I treatment and adhere to treatment recommendations. Older age may facilitate successful utilization of treatment through increases in conscientiousness. The personality trait of conscientiousness increases over the life span with the greatest increase shown in facets of impulse control (higher levels of cautiousness and lower levels of carelessness) and reliability (higher levels of dependability and lower levels of unreliability; Jackson et al., 2009). The finding that older adults more reliably show up to treatment and resist urges to deviate from a set bed and wake time may be due in part to older adults having a higher level of conscientiousness on average as compared to younger adults. Tailoring treatments to individual characteristics has been shown to improve treatment utilization (Bosworth et al., 2006). For example, tailoring health messages promoting mammography to an individual's style of coping was more effective than untailored messages (Williams-Piehota, Pizarro, Schneider, Mowad, \& Salovey, 2005). Future studies may investigate mediators of the relationship between age and treatment utilization, such as level of conscientiousness, in order to design a CBT-I treatment program that is more tailored towards the preferences and needs of younger adults.

According to the Health Belief Model, an individual's decision to attend treatment and adhere to treatment recommendations is influenced by their perception of barriers that will 
hinder their ability to utilize treatment successfully (Martin et al., 2010). Individuals may perceive having more co-occurring symptoms of other mental health disorders (e.g., depression, anxiety) as barriers to their ability to utilize CBT-I treatment successfully. The present study found lower levels of anxiety and depressive symptoms to be associated with greater likelihood of attending three or more sessions and completing all recommended sessions of CBT-I treatment. Additionally, less depressive symptoms were associated with less deviation in wake times. Symptoms of depression such as low energy may hinder an individual's ability to physically attend session as well as physically comply with various treatment recommendations such as getting out of bed at a consistent time every morning (Smith, Huang, \& Manber, 2005). Additionally, cognitive symptoms of depression such as pessimism may negatively impact an individual's perceived ability to attend treatment, follow treatment recommendations, or benefit from treatment even if they do attend all sessions and follow all recommendations.

Individuals with high levels of anxiety may be less likely to utilize a treatment that recommends restricting sleep so that they would be sleeping even less than ever before. These individuals are likely already very worried about the negative impact of limited sleep and likely possess several catastrophizing beliefs related to not getting enough sleep (Smith et al., 2005). Unfortunately, cognitive restructuring occurs near the end of the treatment, while sleep restriction occurs near the beginning of the treatment. Consequently, anxious individuals who are already worried about the negative impact of their limited sleep may have been more likely to attend only two or fewer sessions before dropping out since it is in the second session that they are presented with the treatment rationale which includes recommendations to restrict sleep even further (Smith et al., 2005). Among individuals who did attend treatment, however, anxiety symptoms did not appear to hinder an individual's ability to comply with treatment 
recommendations (i.e., follow a consistent bed and wake time). It may be that highly anxious people are more skeptical of the treatment and may be less likely to buy into the rationale and decide to remain in treatment. However, among anxious individuals who came to treatment, higher anxiety symptoms did not appear to hinder their ability to adhere to treatment recommendations.

Depression and anxiety symptoms are highly comorbid with symptoms of insomnia (Espie et al., 2007; Taylor, Lichstein, Durrence, Reidel, \& Bush, 2005). Given the negative impact of co-occurring depression and anxiety symptoms on CBT-I treatment attendance, these symptoms should be assessed in all individuals seeking insomnia treatment. To facilitate better treatment attendance, clinicians may work with the individual to determine whether the cooccurring symptoms may negatively impact treatment attendance and refer the individual to obtain treatment for their depression or anxiety before beginning CBT-I treatment. The symptoms of depression and anxiety may also hinder motivation to utilize CBT-I treatment and thus additional time spent assessing and securing buy-in from these individuals may be warranted. Providing didactics on the importance of getting insomnia treated as it is a risk factor for developing depressive or anxiety disorders (Neckelmann et al., 2007; Riemann \& Voderholzer, 2003) and the treatment of which may improve co-occurring mental health symptoms (Manber et al., 2008) may assist in increasing buy in from individuals with co-morbid anxiety and/or depressive symptoms. Additionally, the use of motivational interviewing prior to treatment may also facilitate attendance and adherence among these individuals (VanBuskirk \& Wetherell, 2014).

The Health Belief Model states that an individual's decision to utilize treatment is influenced by their perception of need for treatment (e.g., perceived symptom severity and/or 
severity of prognosis of their disease; Martin et al., 2010). The present study found that individuals with lower insomnia symptoms at the beginning of treatment were more likely to complete all recommended treatment sessions, which is inconsistent with the Health Belief Model. However, insomnia symptom severity was not associated with likelihood of completing three or more sessions or with the number of sessions attended among individuals who did not attend all recommended sessions. The findings in the literature regarding baseline sleep problem severity and attendance are also mixed, with two studies indicating that greater sleep problems at the beginning of treatment (i.e., greater fatigue, Dashevsk \& Kramer,1997; and lower total sleep time, Ong et al., 2008) were associated with greater attrition and one study indicating that less sleep disturbance at baseline was associated with greater attrition (Morgan et al., 2003). Additionally, other measures of sleep problems used in our study (i.e., sleep problem severity, PSQI, and daytime sleepiness, ESS) were not associated with attendance. These findings suggest that pre-treatment sleep problem severity may not be a reliable predictor of treatment attendance. It is important to note that this study investigated a broad range of potential predictors (predictors that may predispose an individual to utilize treatment, enable an individual to utilize treatment, signal a need to the individual to utilize treatment) with very few predictors being found to be associated with attendance of CBT-I treatment or adherence to CBT-I recommendations. Gender, ethnicity, and level of education, factors that may predispose individuals to utilize treatment, were not associated with attendance or adherence in this treatment study. Additionally, employment status, insurance status, marital status, and number of co-occurring health problems, factors that may help enable an individual to utilize treatment, were also not found to be associated with attendance and adherence. Co-occurring depression and anxiety symptoms did not predict adherence and did not predict attendance over and above 
age. Lastly, factors that may signal to the individual that there is a need to seek out treatment showed limited and inconsistent relations to attendance and adherence. These findings suggest that patient factors are limited in their utility in predicting CBT-I treatment utilization. Patient factors are also the most commonly investigated predictors of CBT-I treatment utilization (e.g., Bouchard et al., 2003; Manber et al., 2011; Vincent et al., 2008). Given their limited utility, clinicians have recommended investigating factors associated with the therapist or the treatment that may influence treatment utilization (Bosworth et al., 2006).

Past psychotherapy research has indicated that individuals were more likely to attend treatment if they had a stronger therapeutic alliance with their therapist (Keller, Zoellner, \& Feeny, 2010; Simpson, Joe, Rowan-Szal, \& Greener, 1997; Taft et al., 2003). A better therapeutic alliance was also associated with increased compliance with recommended homework (Taft, Murphy, King, Musser, \& DeDeyn, 2003). Psychotherapy studies have found a number of therapist characteristics associated with retention of patients include being female, older, more motivated, more caring, and more experienced (Swift \& Greenberg, 2012, Tryon, 1985; Tryon, 1989; Tryon \& Tryon, 1986). Patients were also more likely to comply with treatment recommendations if their therapist was female and more skilled (Bryant et al., 1999). To date, no CBT-I treatment studies have investigated therapist factors (e.g., therapist gender, therapist skill) and treatment factors (e.g., therapeutic alliance) associated with CBT-I attendance and adherence to CBT-I recommendations. The limited success of CBT-I treatment studies to identify patient characteristics that consistently predict treatment utilization provide support for the need to investigate therapist and treatment factors to find consistent predictors of CBT-I treatment utilization.

The present study has several limitations that may influence the interpretation and 
generalizability of the findings. The sample was primarily Caucasian and thus findings may not generalize to more heterogeneous samples. Added caution is warranted with respect to interpreting the nonsignificant relation between ethnicity and attendance and adherence as $92 \%$ of the sample was Caucasian. All therapies were provided by first and second year clinical psychology graduate students and thus caution is warranted in generalizing the findings of this study to CBT-I treatments carried out by more experienced psychotherapists. Of note, all student therapists were supervised by a licensed clinical psychologist certified in behavioural sleep medicine. Attrition levels were higher in the present study as compared to what is generally seen in CBT-I treatment, which may be due in part to the fact that all treatments were carried out by graduate students early in their training. The limited number of participants in the treatment completion group meant that there was insufficient power to analyse predictors of treatment completion in multivariate analyses to determine if the predictors that were significant in univariate analyses would still contribute unique predictive utility in multivariate analyses. The biographical questionnaire assessing relationship status did not provide an option to select living together and thus the present study was not able to investigate the relation between cohabitation and treatment utilization. This information should be considered when interpreting the results of the analyses investigating the relation between marital status and treatment utilization. Replication of the findings of the study, in particular with respect to predictors of treatment completion, is warranted. Despite these limitations, the present study fills a gap in the literature by systematically investigating a broad array of factors that may be associated with CBT-I treatment attendance and adherence using a heterogeneous community sample of adults with insomnia disorder. The study utilized few inclusion and exclusion criteria in order to ensure the recruitment of a heterogeneous treatment seeking sample which provides support for the 
generalizability of our findings.

The present study investigated factors associated with attending CBT-I and adhering to CBT-I treatment. Older adults and individuals with less co-occurring depression and anxiety symptomology were more likely to attend treatment and older adults were also more likely to adhere to treatment recommendations of maintaining a consistent bed and wake time. Assessing and addressing co-occurring mental health problems through treatment or referral may improve CBT-I treatment retention. Research identifying mediators of the relation between age and treatment utilization and designing CBT-I treatments tailored towards the needs of younger adults may improve retention of younger adults and their adherence to treatment recommendations. 


\section{References}

American Psychiatric Association. (2000). Diagnostic and statistical manual of mental disorders (4th ed., text rev.). American Psychiatric Pub.

American Psychiatric Association. (2013). Diagnostic and statistical manual of mental disorders (5th ed.). American Psychiatric Pub.

Andersen, R. M. (1995). Revisiting the behavioral model and access to medical care: Does it matter?. Journal of Health and Social Behavior, 36, 1-10.

Anthony, M. N., Gardner, L., Marks, G., Anderson-Mahoney, P., Metsch, L. R., Valverde, E. E., \& ... Loughlin, A. M. (2007). Factors associated with use of HIV primary care among persons recently diagnosed with HIV: Examination of variables from the behavioural model of health-care utilization. AIDS Care, 19, 195-202.

Backhaus, J., Hohagen, F., Voderholzer, U., \& Riemann, D. (2001). Long-term effectiveness of a short-term cognitive-behavioral group treatment for primary insomnia. European Archives of Psychiatry and Clinical Neuroscience, 251, 35-41.

Baekeland, F., \& Lundwall, L. (1975). Dropping out of treatment: A critical review. Psychological Bulletin, 82, 738-783.

Barrett, M. S., Chua, W. J., Crits-Christoph, P., Gibbons, M. B., \& Thompson, D. (2008). Early withdrawal from mental health treatment: Implications for psychotherapy practice. Psychotherapy: Theory, Research, Practice, Training, 45, 247-267.

Bastien, C. H., Vallières, A., \& Morin, C. M. (2001). Validation of the Insomnia Severity Index as an outcome measure for insomnia research. Sleep Medicine, 2, 297-307.

Baum, O. E., \& Felzer, S. B. (1964). Activity in initial interviews with lower-class patients. Archives of General Psychiatry, 10, 345-353. 
Beck, A. T., Epstein, N., Brown, G., \& Steer, R. A. (1988). An inventory for measuring clinical anxiety: psychometric properties. Journal of Consulting and Clinical Psychology, 56, 893-897.

Bolge, S. C., Doan, J. F., Kannan, H., \& Baran, R. W. (2009). Association of insomnia with quality of life, work productivity, and activity impairment. Quality of Life Research, $18,415-422$.

Bosworth, H. B., Oddone, E. Z., \& Weinberger, M. (Eds.). (2006). Patient treatment adherence: concepts, interventions, and measurement. Psychology Press.

Bouchard, S., Bastien, C., \& Morin, C. M. (2003). Self-Efficacy and Adherence to CognitiveBehavioral Treatment of Insomnia. Behavioral Sleep Medicine, 1, 187-199.

Brill, N. Q., \& Storrow, H. A. (1960). Social class and psychiatric treatment. Archives of General Psychiatry, 3, 340-344.

Brown, C., Barner, J., Bohman, T., \& Richards, K. (2009). A multivariate test of an expanded Andersen Health Care utilization model for complementary and alternative medicine (CAM) use in African Americans. The Journal of Alternative and Complementary Medicine, 15, 911-919.

Bryant, M. J., Simons, A. D., \& Thase, M. E. (1999). Therapist skill and patient variables in homework compliance: Controlling an uncontrolled variable in cognitive therapy outcome research. Cognitive Therapy and Research, 23, 381-399.

Burns, D. D., \& Nolen-Hoeksema, S. (1991). Coping styles, homework compliance, and the effectiveness of cognitive-behavioral therapy. Journal of Consulting and Clinical Psychology, 59, 305-311.

Burns, D. D., \& Spangler, D. L. (2000). Does psychotherapy homework lead to improvements in 
depression in cognitive-behavioral therapy or does improvement lead to increased homework compliance?. Journal of Consulting and Clinical Psychology, 68, 46-56.

Buysse, D. J., Hall, M. L., Strollo, P. J., Kamarck, T. W., Owens, J., Lee, L., ... \& Matthews, K. A. (2008). Relationships between the Pittsburgh Sleep Quality Index (PSQI), Epworth Sleepiness Scale (ESS), and clinical/polysomnographic measures in a community sample. Journal of Clinical Sleep Medicine, 4, 563-571.

Buysse, D. J., Reynolds, C. F., Monk, T. H., Berman, S. R., \& Kupfer, D. J. (1989). The Pittsburgh Sleep Quality Index: a new instrument for psychiatric practice and research. Psychiatry Research, 28, 193-213.

Cohen, S., Mermelstein, R., Kamarck, T., \& Hoberman, H. M. (1985). Measuring the functional components of social support. In Social support: Theory, research and applications (pp. 73-94). Springer Netherlands.

Cole, M. G., \& Dendukuri, N. (2003). Risk Factors for Depression Among Elderly Community Subjects: A Systematic Review and Meta-Analysis. The American Journal of Psychiatry, 160, 1147-1156.

Cui, R., Haller, M., Skidmore, J. R., Goldsteinholm, K., Norman, S., \& Tate, S. R. (2016). Treatment attendance among veterans with depression, substance use disorder, and trauma. Journal of Dual Diagnosis, 12, 15-26.

Daley, M., Morin, C. M., LeBlanc, M., Gregoire, J. P., Savard, J., \& Baillargeon, L. (2009). Insomnia and its relationship to health-care utilization, work absenteeism, productivity and accidents. Sleep Medicine, 10, 427-438.

Dashevsky, B., \& Kramer, M. (1997). Patients who discontinue combined behavioral and medicinal treatment of insomnia. Sleep Research, 26, 350. 
Decker, S. E., Kiluk, B. D., Frankforter, T., Babuscio, T., Nich, C., \& Carroll, K. M. (2016). Just showing up is not enough: Homework adherence and outcome in cognitive-behavioral therapy for cocaine dependence. Journal of Consulting and Clinical Psychology, 84, 907-912.

Derisley, J., \& Reynolds, S. (2000). The transtheoretical stages of change as a predictor of premature termination, attendance and alliance in psychotherapy. British Journal of Clinical Psychology, 39, 371-382.

Dew, M. A., Hoch, C. C., Buysse, D. J., Monk, T. H., Begley, A. E., Houck, P. R., ... \& Reynolds III, C. F. (2003). Healthy older adults'sleep predicts all-cause mortality at 4 to 19 years of follow-up. Psychosomatic Medicine, 65, 63-73.

Dush, C. M. K., \& Amato, P. R. (2005). Consequences of relationship status and quality for subjective well-being. Journal of Social and Personal Relationships, 22, 607-627.

Eaton, W. W., Smith, C., Ybarra, M., Muntaner, C., \& Tien, A. (2004). Center for Epidemiologic Studies Depression Scale: Review and Revision (CESD and CESD-R). In M. E. Maruish, M. E. Maruish (Eds.), The use of psychological testing for treatment planning and outcomes assessment: Instruments for adults, Volume 3, 3rd ed (pp. 363-377). Mahwah, NJ, US: Lawrence Erlbaum Associates Publishers.

Edelman, R. E., \& Chambless, D. L. (1993). Compliance during sessions and homework in exposure-based treatment of agoraphobia. Behaviour Research and Therapy, 31, 767773.

Edelman, R. E., \& Chambless, D. L. (1995). Adherence during sessions and homework in cognitive-behavioral group treatment of social phobia. Behaviour Research and Therapy, 33, 573-577. 
Edinger, J. D., \& Means, M. K. (2005). Cognitive-behavioral therapy for primary insomnia. Clinical Psychology Review, 25, 539-558.

Edinger, J. D., Olsen, M. K., Stechuchak, K. M., Means, M. K., Lineberger, M. D., Kirby, A., \& Carney, C. E. (2009). Cognitive behavioral therapy for patients with primary insomnia or insomnia associated predominantly with mixed psychiatric disorders: a randomized clinical trial. Sleep: Journal of Sleep and Sleep Disorders Research, 32, 499-510.

Edinger, J. D., Wohlgemuth, W. K., Radtke, R. A., Coffman, C. J., \& Carney, C. E. (2007). Dose-response effects of cognitive-behavioral insomnia therapy: A randomized clinical trial. Sleep: Journal of Sleep and Sleep Disorders Research, 30, 203-212.

Edinger, J. D., Wohlgemuth, W. K., Radtke, R. A., Marsh, G. R., \& Quillian, R. E. (2001). Cognitive behavioral therapy for treatment of chronic primary insomnia: a randomized controlled trial. JAMA: Journal of the American Medical Association, 285, 1856-1864.

Espie, C. A., Fleming, L., Cassidy, J., Samuel, L., Taylor, L. M., White, C. A., ... \& Paul, J. (2008). Randomized controlled clinical effectiveness trial of cognitive behavior therapy compared with treatment as usual for persistent insomnia in patients with cancer. Journal of Clinical Oncology, 26, 4651-4658.

Espie, C. A., Inglis, S. J., Tessier, S., \& Harvey, L. (2001). The clinical effectiveness of cognitive behaviour therapy for chronic insomnia: implementation and evaluation of a sleep clinic in general medical practice. Behaviour Research and Therapy, 39, 45-60.

Espie, C. A., MacMahon, K. A., Kelly, H., Broomfield, N. M., Douglas, N. J., Engleman, H. M., \& ... Wilson, P. (2007). Randomized clinical effectiveness trial of nurse-administered small-group cognitive behavior therapy for persistent insomnia in general practice. Sleep: Journal of Sleep and Sleep Disorders Research, 30, 574-584. 
Faul, F., Erdfelder, E., Lang, A. G., \& Buchner, A. (2007). G* Power 3: a flexible statistical power analysis program for the social, behavioral, and biomedical sciences. Behavior Research Methods, 39, 175-191.

Fehm, L., \& Mrose, J. (2008). Patients' perspective on homework assignments in cognitivebehavioural therapy. Clinical Psychology \& Psychotherapy, 15, 320-328.

Funk, A. P., Zvolensky, M. J., \& Schmidt, N. B. (2011). Homework compliance in a brief cognitive-behavioural and pharmacological intervention for smoking. Journal of Smoking Cessation, 6, 99-111.

Gonzalez, V. M., Schmitz, J. M., \& DeLaune, K. A. (2006). The role of homework in cognitivebehavioral therapy for cocaine dependence. Journal of Consulting and Clinical Psychology, 74, 633-637.

Good, G. E., Dell, D. M., \& Mintz, L. B. (1989). Male role and gender role conflict: Relations to help seeking in men. Journal of Counseling Psychology, 36, 295-300.

Goodwin, R., \& Andersen, R. M. (2002). Use of the behavioral model of health care use to identify correlates of use of treatment for panic attacks in the community. Social Psychiatry and Psychiatric Epidemiology, 37, 212-219.

Gross, J. J., \& John, O. P. (2003). Individual differences in two emotion regulation processes: implications for affect, relationships, and well-being. Journal of Personality and Social Psychology, 85, 348-362.

Gustavsen, I., Bramness, J. G., Skurtveit, S., Engeland, A., Neutel, I., \& Mørland, J. (2008). Road traffic accident risk related to prescriptions of the hypnotics zopiclone, zolpidem, flunitrazepam and nitrazepam. Sleep Medicine, 9, 818-822.

Hays, R.B., Chauncy, S. \& Tobey, L.A. (1990). The social support networks of gay men with 
AIDS. American Journal of Community Psychology, 18, 743-755.

Helbig, S., \& Fehm, L. (2004). Problems with Homework in CBT: Rare Exception or Rather Frequent?. Behavioural and Cognitive Psychotherapy, 32, 291-301.

Holdsworth, E., Bowen, E., Brown, S., \& Howat, D. (2014). Client engagement in psychotherapeutic treatment and associations with client characteristics, therapist characteristics, and treatment factors. Clinical Psychology Review, 34, 428-450.

Irwin, M. R., Cole, J. C., \& Nicassio, P. M. (2006). Comparative meta-analysis of behavioral interventions for insomnia and their efficacy in middle-aged adults and in older adults 55+ years of age. Health Psychology, 25, 3-14.

Jackson, J. J., Bogg, T., Walton, K. E., Wood, D., Harms, P. D., Lodi-Smith, J., \& ... Roberts, B. W. (2009). Not all conscientiousness scales change alike: A multimethod, multisample study of age differences in the facets of conscientiousness. Journal of Personality and Social Psychology, 96, 446-459.

Jacobs, G. D., Pace-Schott, E. F., Stickgold, R., \& Otto, M. W. (2004). Cognitive behavior therapy and pharmacotherapy for insomnia: a randomized controlled trial and direct comparison. Archives of Internal Medicine, 164, 1888-1896.

Johns, M. W. (1991). A new method for measuring daytime sleepiness: the Epworth sleepiness scale. Sleep: Journal of Sleep Research \& Sleep Medicine, 14, 540-545.

Johns, M. W. (1992). Reliability and factor analysis of the Epworth Sleepiness Scale. Sleep: Journal of Sleep Research \& Sleep Medicine, 15, 376-381.

Kabacoff, R. I., Segal, D. L., Hersen, M., \& Van Hasselt, V. B. (1997). Psychometric properties and diagnostic utility of the Beck Anxiety Inventory and the State-Trait Anxiety Inventory with older adult psychiatric outpatients. Journal of Anxiety Disorders, 11, 
$33-47$.

Keller, S. M., Zoellner, L. A., \& Feeny, N. C. (2010). Understanding factors associated with early therapeutic alliance in PTSD treatment: Adherence, childhood sexual abuse history, and social support. Journal of Consulting and Clinical Psychology, 78, 974-979.

Keyes, K. M., Hatzenbuehler, M. L., Alberti, P., Narrow, W. E., Grant, B. F., \& Hasin, D. S. (2008). Service utilization differences for Axis I psychiatric and substance use disorders between white and black adults. Psychiatric Services, 59, 893-901.

Kohn, L., \& Espie, C. A. (2005). Sensitivity and specificity of measures of the insomnia experience: a comparative study of psychophysiologic insomnia, insomnia associated with mental disorder and good sleepers. Sleep: Journal of Sleep and Sleep Disorders Research, 28, 104-112.

LeBeau, R. T., Davies, C. D., Culver, N. C., \& Craske, M. G. (2013). Homework compliance counts in cognitive-behavioral therapy. Cognitive Behaviour Therapy, 42, 171-179.

Leger, D., \& Poursain, B. (2005). An international survey of insomnia: under-recognition and under-treatment of a polysymptomatic condition. Current Medical Research and Opinion, 21, 1785-1792.

Lorion, R. P. (1974). Patient and therapist variables in the treatment of low-income patients. Psychological Bulletin, 81, 344-354.

Manber, R., Bernert, R. A., Suh, S., Nowakowski, S., Siebern, A. T., \& Ong, J. C. (2011). CBT for insomnia in patients with high and low depressive symptom severity: adherence and clinical outcomes. Journal of Clinical Sleep Medicine, 7, 645-652.

Manber, R., Edinger, J. D., Gress, J. L., Pedro-Salcedo, M. S., Kuo, T. F., \& Kalista, T. (2008). Cognitive behavioral therapy for insomnia enhances depression outcome in patients with 
comorbid major depressive disorder and insomnia. Sleep: Journal of Sleep and Sleep Disorders Research, 31, 489-495.

Martin, L. R., Haskard-Zolnierek, K. B., \& DiMatteo, M. R. (2010). Health behavior change and treatment adherence: Evidence-based guidelines for improving healthcare. Oxford University Press, USA.

Matthews, E. E., Arnedt, J. T., McCarthy, M. S., Cuddihy, L. J., \& Aloia, M. S. (2013). Adherence to cognitive behavioral therapy for insomnia: A systematic review. Sleep Medicine Reviews, 17, 453-464.

Montgomery, P., \& Dennis, J. (2004). A systematic review of non-pharmacological therapies for sleep problems in later life. Sleep Medicine Reviews, 8, 47-62.

Morgan, K., Thompson, J., Dixon, S., Tomeny, M., \& Mathers, N. (2003). Predicting longerterm outcomes following psychological treatment for hypnotic-dependent chronic insomnia. Journal of Psychosomatic Research, 54, 21-29.

Morin, C. M., Belleville, G., Bélanger, L., \& Ivers, H. (2011). The Insomnia Severity Index: psychometric indicators to detect insomnia cases and evaluate treatment response. Sleep: Journal of Sleep and Sleep Disorders Research, 34, 601-608.

Morin, C. M., Bootzin, R. R., Buysse, D. J., Edinger, J. D., Espie, C. A., \& Lichstein, K. L. (2006). Psychological and behavioral treatment of insomnia: Update of the recent evidence (1998-2004). Sleep: Journal of Sleep and Sleep Disorders Research, 29, 13981414.

Morin, C. M., Colecchi, C., Stone, J., Sood, R., \& Brink, D. (1999). Behavioral and pharmacological therapies for late-life insomnia: a randomized controlled trial. JAMA: Journal of the American Medical Association, 281, 991-999. 
Morin, C. M., LeBlanc, M., Daley, M., Gregoire, J. P., \& Merette, C. (2006). Epidemiology of insomnia: prevalence, self-help treatments, consultations, and determinants of helpseeking behaviors. Sleep Medicine, 7, 123-130.

Morphy, H., Dunn, K. M., Lewis, M., Boardman, H. F., \& Croft, P. R. (2007). Epidemiology of insomnia: A longitudinal study in a UK population. Sleep: Journal of Sleep and Sleep Disorders Research, 30, 274-280.

National Institutes of Health. (2005). National Institutes of Health State of the Science Conference statement on Manifestations and Management of Chronic Insomnia in Adults, June 13-15, 2005. Sleep: Journal of Sleep and Sleep Disorders Research, 28, 1049-1057.

Neckelmann, D., Mykletun, A., \& Dahl, A. A. (2007). Chronic insomnia as a risk factor for developing anxiety and depression. Sleep: Journal of Sleep and Sleep Disorders Research, 30, 873-880.

Ohayon, M. M. (2002). Epidemiology of insomnia: What we know and what we still need to learn. Sleep Medicine Reviews, 6, 97-111.

Ong, J. C., Kuo, T. F., \& Manber, R. (2008). Who is at risk for dropout from group cognitivebehavior therapy for insomnia? Journal of Psychosomatic Research, 64, 419-425.

Ozminkowski, R. J., Wang, S., \& Walsh, J. K. (2007). The direct and indirect costs of untreated insomnia in adults in the United States. Sleep: Journal of Sleep and Sleep Disorders Research, 30, 263-273.

Peduzzi, P., Concato, J., Kemper, E., Holford, T. R., \& Feinstein, A. R. (1996). A simulation study of the number of events per variable in logistic regression analysis. Journal of Clinical Epidemiology, 49(12), 1373-1379. 
Pekarik, G. (1992). Posttreatment adjustment of clients who drop out early vs. late in treatment. Journal of Clinical Psychology, 48, 379-387.

Peterson, R. A., \& Heilbronner, R. L. (1987). The Anxiety Sensitivity Index: Construct validity and factor analytic structure. Journal of Anxiety Disorders, 1, 117-121.

Peterson, R. A., \& Plehn, K. (1999). Measuring anxiety sensitivity. In S. Taylor, S. Taylor (Eds.). Anxiety sensitivity: Theory, research, and treatment of the fear of anxiety (pp. 6181). Mahwah, NJ, US: Lawrence Erlbaum Associates Publishers.

Perlis, M. L., Jungquist, C., Smith, M. T., \& Posner, D. (2006). Cognitive behavioral treatment of insomnia: A session-by-session guide (Vol. 1). Springer Science \& Business Media.

Qaseem, A., Kansagara, D., Forciea, M. A., Cooke, M., \& Denberg, T. D. (2016). Management of Chronic Insomnia Disorder in Adults: A Clinical Practice Guideline From the American College of Physicians. Annals of Internal Medicine, 165, 125-133.

Rabkin, J.G., Williams, J.B.W., Neugebauer, R., Remien, R.H. \& Goetz, R. (1990). Maintenance of hope in HIV-spectrum homosexual men. American Journal of Psychiatry, 147, 13221326.

Rees, C. S., McEvoy, P., \& Nathan, P. R. (2005). Relationship between homework completion and outcome in cognitive behaviour therapy. Cognitive Behaviour Therapy, 34, 242247.

Reis, B. F., \& Brown, L. G. (1999). Reducing psychotherapy dropouts: Maximizing perspective convergence in the psychotherapy dyad. Psychotherapy: Theory, Research, Practice, Training, 36, 123-136.

Riedel, B. W., \& Lichstein, K. L. (2001). Strategies for evaluating adherence to sleep restriction treatment for insomnia. Behaviour Research and Therapy, 39, 201-212. 
Riemann, D., \& Voderholzer, U. (2003). Primary insomnia: a risk factor to develop depression?. Journal of Affective Disorders, 76, 255-259.

Roth, T., \& Roehrs, T. (2003). Insomnia: epidemiology, characteristics, and consequences. Clinical Cornerstone, 5, 5-15.

Sachsenweger, M. A., Fletcher, R. B., \& Clarke, D. (2015). Pessimism and homework in CBT for depression. Journal of Clinical Psychology, 71, 1153-1172.

Samuel, M. J. (2015). American Geriatrics Society 2015 updated Beers Criteria for potentially inappropriate medication use in older adults. Journal of the American Geriatrics Society, 63, 2227-2246.

Sasso, K. E., Strunk, D. R., Braun, J. D., DeRubeis, R. J., \& Brotman, M. A. (2015). Identifying moderators of the adherence-outcome relation in cognitive therapy for depression. Journal of Consulting and Clinical Psychology, 83, 976-984.

Schmidt, N. B., \& Woolaway-Bickel, K. (2000). The effects of treatment compliance on outcome in cognitive-behavioral therapy for panic disorder: Quality versus quantity. Journal of Consulting and Clinical Psychology, 68, 13-18.

Self, R., Oates, P., Pinnock-Hamilton, T., \& Leach, C. (2005). The relationship between social deprivation and unilateral termination (attrition) from psychotherapy at various stages of the health care pathway. Psychology and Psychotherapy: Theory, Research and Practice, 78, 95-111.

Simpson, D. D., Joe, G. W., Rowan-Szal, G. A., \& Greener, J. M. (1997). Drug abuse treatment process components that improve retention. Journal of Substance Abuse Treatment, 14, $565-572$.

Sivertsen, B., Omvik, S., Pallesen, S., Bjorvatn, B., Havik, O. E., Kvale, G., ... \& Nordhus, I. H. 
(2006). Cognitive behavioral therapy vs zopiclone for treatment of chronic primary insomnia in older adults: a randomized controlled trial. JAMA: Journal of the American Medical Association, 295, 2851-2858.

Smith, M. T., Huang, M. I., \& Manber, R. (2005). Cognitive behavior therapy for chronic insomnia occurring within the context of medical and psychiatric disorders. Clinical Psychology Review, 25, 559-592.

Smith, M. T., \& Perlis, M. L. (2006). Who is a candidate for cognitive-behavioral therapy for insomnia?. Health Psychology, 25, 15-19.

Smith, M. T., Perlis, M. L., Park, A., Smith, M. S., Pennington, J., Giles, D. E., \& Buysse, D. J. (2002). Comparative meta-analysis of pharmacotherapy and behavior therapy for persistent insomnia. The American Journal of Psychiatry, 159, 5-10.

Smith, M. T., \& Wegener, S. T. (2003). Measures of sleep: the insomnia severity index, medical outcomes study (MOS) sleep scale, Pittsburgh sleep diary (PSD), and Pittsburgh sleep quality index (PSQI). Arthritis Care \& Research, 49, S184-S196.

Stepanski, E. J., \& Rybarczyk, B. (2006). Emerging research on the treatment and etiology of secondary or comorbid insomnia. Sleep Medicine Reviews, 10, 7-18.

Sue, S. (1977). Community mental health services to minority groups: Some optimism, some pessimism. American Psychologist, 32, 616-624.

Swift, J. K., \& Greenberg, R. P. (2012). Premature discontinuation in adult psychotherapy: A meta-analysis. Journal of Consulting and Clinical Psychology, 80, 547-559.

Taft, C. T., Murphy, C. M., King, D. W., Musser, P. H., \& DeDeyn, J. M. (2003). Process and treatment adherence factors in group cognitive-behavioral therapy for partner violent men. Journal of Consulting and Clinical Psychology, 71, 812-820. 
Tariq, S. H., \& Pulisetty, S. (2008). Pharmacotherapy for insomnia. Clinics in Geriatric Medicine, 24, 93-105.

Tate, S. R., Mrnak-Meyer, J., Shriver, C. L., Atkinson, J. H., Robinson, S. K., \& Brown, S. A. (2011). Predictors of treatment retention for substance-dependent adults with cooccurring depression. The American Journal on Addictions, 20, 357-365.

Taylor, D. J., Lichstein, K. L., \& Durrence, H. H. (2003). Insomnia as a health risk factor. Behavioral Sleep Medicine, 1, 227-247.

Taylor, D. J., Lichstein, K. L., Durrence, H. H., Riedel, B. W., \& Bush, A. J. (2005). Epidemiology of insomnia, depression, and anxiety. Sleep: Journal of Sleep and Sleep Disorders Research, 28, 1457-1464.

Taylor, D. J., Mallory, L. J., Lichstein, K. L., Durrence, H. H., Riedel, B. W., \& Bush, A. J. (2007). Comorbidity of chronic insomnia with medical problems. Sleep: Journal of Sleep and Sleep Disorders Research, 30, 213-218.

Tryon, G. S. (1985). The engagement quotient: One index of a basic counseling task. Journal of College Student Personnel, 26, 351-354.

Tryon, G. S. (1989). A study of engagement and premature termination in a university counseling center. Counselling Psychology Quarterly, 2, 419-429.

Tryon, G. S., \& Tryon, W. W. (1986). Factors associated with clinical practicum trainees' engagements of clients in counseling. Professional Psychology: Research and Practice, $17,586-589$.

Vallières, A., \& Morin, C. M. (2003). Actigraphy in the assessment of insomnia. Sleep: Journal of Sleep and Sleep Disorders Research, 26, 902-906.

Van Dam, N. T., \& Earleywine, M. (2011). Validation of the Center for Epidemiologic Studies 
Depression Scale-Revised (CESD-R): Pragmatic depression assessment in the general population. Psychiatry Research, 186, 128-132.

VanBuskirk, K. A., \& Wetherell, J. L. (2014). Motivational interviewing with primary care populations: A systematic review and meta-analysis. Journal of Behavioral Medicine, 37, 768-780.

Verster, J. C., Volkerts, E. R., Schreuder, A. L., Eijken, E. E., van Heucklum, J. G., Veldhuijzen, D. S., \& ... Patat, A. (2002). Residual effects of middle of-the-night administration of zaleplon and zolpidem on driving ability, memory functions and psychomotor performance. Journal of Clinical Psychopharmacology, 22, 576-583

Vincent, N. K., \& Hameed, H. (2003). Relation between adherence and outcome in the group treatment of insomnia. Behavioral Sleep Medicine, 1, 125-139.

Vincent, N., Lewycky, S., \& Finnegan, H. (2008). Barriers to engagement in sleep restriction and stimulus control in chronic insomnia. Journal of Consulting and Clinical Psychology, 76, 820-828.

Vincent, N., \& Lionberg, C. (2001). Treatment preference and patient satisfaction in chronic insomnia. Sleep: Journal of Sleep and Sleep Disorders Research, 24, 411-417.

Vittinghoff, E., \& McCulloch, C. E. (2007). Relaxing the rule of ten events per variable in logistic and Cox regression. American Journal of Epidemiology, 165, 710-718.

Weck, F., Richtberg, S., Esch, S., Höfling, V., \& Stangier, U. (2013). The relationship between therapist competence and homework compliance in maintenance cognitive therapy for recurrent depression: Secondary analysis of a randomized trial. Behavior Therapy, 44, $162-172$.

Wierzbicki, M., \& Pekarik, G. (1993). A meta-analysis of psychotherapy dropout. Professional 
Psychology: Research and Practice, 24, 190-195.

Williams-Piehota, P., Pizarro, J., Schneider, T. R., Mowad, L., \& Salovey, P. (2005). Matching Health Messages to Monitor-Blunter Coping Styles to Motivate Screening Mammography. Health Psychology, 24, 58-67.

Willner-Reid, J., Whitaker, D., Epstein, D. H., Phillips, K. A., Pulaski, A. R., Preston, K. L., \& Willner, P. (2016). Cognitive-behavioural therapy for heroin and cocaine use: Ecological momentary assessment of homework simplification and compliance. Psychology and Psychotherapy: Theory, Research and Practice, 89, 276-293.

Zemore, S. E., Mulia, N., Ye, Y., Borges, G., \& Greenfield, T. K. (2009). Gender, acculturation, and other barriers to alcohol treatment utilization among Latinos in three National Alcohol Surveys. Journal of Substance Abuse Treatment, 36, 446-456. 
Table 1.

Demographic Characteristics of the Sample

\begin{tabular}{|c|c|c|c|c|c|}
\hline & Frequency & $(\%)$ & $M$ & $S D$ & $\mathrm{~N}$ \\
\hline \multicolumn{6}{|l|}{ Predisposing Factors } \\
\hline Age & & & 50.45 & 14.63 & 108 \\
\hline Gender & & & & & 108 \\
\hline Female & 77 & $71.30 \%$ & & & \\
\hline Male & 31 & $28.70 \%$ & & & \\
\hline Ethnicity & & & & & 108 \\
\hline Non-Hispanic Caucasian & 100 & $92.60 \%$ & & & \\
\hline African American & 4 & $3.70 \%$ & & & \\
\hline Hispanic American & 1 & $0.90 \%$ & & & \\
\hline Asian American & 2 & $1.90 \%$ & & & \\
\hline Other & 1 & $0.90 \%$ & & & \\
\hline Education & & & & & 106 \\
\hline Less than high school & 8 & $7.40 \%$ & & & \\
\hline High school & 16 & $14.80 \%$ & & & \\
\hline Some college & 20 & $18.50 \%$ & & & \\
\hline Four year college & 27 & $25.00 \%$ & & & \\
\hline Graduate school & 35 & $32.40 \%$ & & & \\
\hline \multicolumn{6}{|l|}{ Enabling Factors } \\
\hline Employment & & & & & 107 \\
\hline Working & 56 & $51.90 \%$ & & & \\
\hline Not working & 17 & $15.70 \%$ & & & \\
\hline Retired & 20 & $18.50 \%$ & & & \\
\hline Disabled & 14 & $13.00 \%$ & & & \\
\hline Insurance & & & & & 108 \\
\hline Private & 80 & $74.10 \%$ & & & \\
\hline Medicare & 17 & $15.70 \%$ & & & \\
\hline Medicaid & 11 & $10.20 \%$ & & & \\
\hline Marital Status & & & & & 108 \\
\hline Married & 48 & $44.40 \%$ & & & \\
\hline Not married & 60 & $55.60 \%$ & & & \\
\hline Number of health problems & & & 3.80 & 3.25 & 108 \\
\hline Beck Anxiety Inventory & & & 13.45 & 10.94 & 101 \\
\hline Center for Epidemiologic & & & & & \\
\hline Studies Depression Scale-Revised & & & 18.83 & 12.86 & 103 \\
\hline \multicolumn{6}{|l|}{ Need Factors } \\
\hline Pittsburgh Sleep Quality Index & & & 14.11 & 3.42 & 100 \\
\hline Epworth Sleepiness Scale & & & 7.54 & 5.98 & 105 \\
\hline Insomnia Severity Index & & & 19.69 & 4.58 & 103 \\
\hline
\end{tabular}


Table 2.

Group vs Individual Cognitive Behavioral Therapy for Insomnia

\begin{tabular}{lcc}
\hline & Group & Individual \\
\hline Attendance & $\mathrm{N}(\%)$ & $\mathrm{N}$ \\
$\quad$ Three or more sessions & $3(43 \%)$ & $47(47 \%)$ \\
All sessions & $0(0 \%)$ & $26(26 \%)$ \\
& & \\
Adherence & $\mathrm{M}(\mathrm{SD})$ & $\mathrm{M}(\mathrm{SD})$ \\
Consistency of Bed Times & $27.54(16.19)$ & $27.05(29.85)$ \\
Consistency of Wake Times & $55.13(7.57)$ & $39.30(26.47)$ \\
\hline
\end{tabular}


Table 3.

Correlation among Continuous Predictor Variables

\begin{tabular}{|c|c|c|c|c|c|c|}
\hline & 2. & 3. & 4. & 5. & 6. & 7. \\
\hline 1. Age & $.30 * *$ & $-.20 *$ & $-.32 * *$ & -.14 & -.07 & -.07 \\
\hline 2. Number of Health Problems & - & $.31 * *$ & .16 & $.26 * *$ & $.21 *$ & $.36 * *$ \\
\hline 3. Beck Anxiety Inventory & & - & $.77 * *$ & $.45 * *$ & .03 & $.50 * *$ \\
\hline $\begin{array}{l}\text { Center for Epidemiologic } \\
\text { 4. Studies Depression Scale-Revised }\end{array}$ & & & - & $.53 * *$ & .17 & $.53 * *$ \\
\hline 5. Pittsburgh Sleep Quality Index & & & & - & .09 & $.55^{* *}$ \\
\hline 6. Epworth Sleepiness Scale & & & & & - & .09 \\
\hline 7. Insomnia Severity Index & & & & & & - \\
\hline
\end{tabular}

Note. $*=\mathrm{p}<.05, * *=\mathrm{p}<.01, \mathrm{~N}$ varies between 103 and 108 due to missing data 
Table 4.

Attended Three or More Sessions vs Two or Fewer Session

\begin{tabular}{lrrr}
\hline & $\mathrm{N}$ & Wald Chi-Square & $p$ \\
\hline Predisposing & & & \\
Age & 108 & 7.43 & $<.01$ \\
Gender & 108 & 0.33 & .56 \\
Ethnicity & 108 & 3.07 & .08 \\
Education & 106 & 0.38 & .54 \\
& & & \\
Enabling & 107 & & \\
Employment & 108 & 6.02 & .11 \\
Insurance & 108 & 0.36 & .84 \\
Marital Status & 108 & 1.56 & .21 \\
Number of Health Problems & 103 & 0.77 & .38 \\
Beck Anxiety Inventory & & 7.53 & $<.01$ \\
Center for Epidemiologic & 107 & & \\
Studies Depression Scale-Revised & & 5.95 & .01 \\
& & & \\
Need & & & \\
Pittsburgh Sleep Quality Index & 104 & 0.52 & .47 \\
Epworth Sleepiness Scale & 107 & 0.003 & .96 \\
Insomnia Severity Index & 105 & 1.80 & .18 \\
\hline Ne. All anlyser were separate bivarian
\end{tabular}

Note. All analyses were separate bivariate logistic regressions 
Table 5.

Predicting Attending Three or More Sessions

\begin{tabular}{|c|c|c|c|c|c|}
\hline Hierarchical Logistic Regression & $-2 \mathrm{LL}$ & $B$ & $S E$ & $\begin{array}{l}\text { Wald Chi- } \\
\text { Square }\end{array}$ & $p$ \\
\hline Step 1. & 140.822 & & & 7.43 & $<.01$ \\
\hline Age & & .04 & .01 & 7.43 & $<.01$ \\
\hline Step 2. & 133.32 & & & 11.89 & $<.01$ \\
\hline Age & & .04 & .02 & 5.27 & .02 \\
\hline Beck Anxiety Inventory & & -.07 & .03 & 4.05 & 0.0497 \\
\hline $\begin{array}{l}\text { Center for Epidemiologic } \\
\text { Studies Depression Scale-Revised }\end{array}$ & & .01 & .03 & 0.29 & .62 \\
\hline
\end{tabular}

Note. Hierarchical logistic regression with age entered into step one and anxiety and depression symptoms entered into step two of model 
Table 6.

Attended All Sessions vs Did Not Attend All Sessions

\begin{tabular}{lrrr}
\hline & $\mathrm{N}$ & Wald Chi-Square & $p$ \\
\hline Predisposing & & & \\
Age & 108 & 10.51 & $<.01$ \\
Gender & 108 & 1.47 & .23 \\
Ethnicity & 108 & 0.002 & .97 \\
Education & 106 & 1.01 & .31 \\
& & & \\
Enabling & & & \\
Employment & 107 & 4.74 & .19 \\
Insurance & 108 & 0.75 & .69 \\
Marital Status & 108 & 0.43 & .51 \\
Number of Health Problems & 108 & 0.45 & .50 \\
Beck Anxiety Inventory & 103 & 5.15 & .02 \\
Center for Epidemiologic & 107 & & $<.01$ \\
Studies Depression Scale-Revised & & & \\
& & & \\
Need & & 0.21 & .65 \\
Pittsburgh Sleep Quality Index & 104 & 0.005 & .94 \\
Epworth Sleepiness Scale & 107 & 5.37 & .02 \\
Insomnia Severity Index & 105 & & \\
\hline
\end{tabular}

Note. All analyses were separate bivariate logistic regressions 
Table 7.

Number of Sessions Attended among Treatment Non-completers

\begin{tabular}{lrrrr}
\hline & $\mathrm{N}$ & $\mathrm{B}$ & $\mathrm{SE}$ & $p$ \\
\hline Predisposing & & & & \\
Age & 82 & 0.03 & 0.01 & .03 \\
Gender & 82 & 0.22 & 0.43 & .61 \\
Ethnicity & 82 & 0.87 & 0.67 & .20 \\
$\quad$ Education & & 0.32 & 0.47 & .50 \\
& & & & \\
Enabling & 81 & -0.27 & 0.17 & .13 \\
$\quad$ Employment & 82 & 0.04 & 0.28 & .88 \\
Insurance & 82 & -0.68 & 0.40 & .09 \\
Marital Status & 82 & -0.01 & 0.06 & .84 \\
$\quad$ Number of Health Problems & 78 & -0.03 & 0.02 & .07 \\
Beck Anxiety Inventory & 81 & -0.01 & 0.02 & .42 \\
Center for Epidemiologic & & & & \\
Studies Depression Scale-Revised & & & & \\
$\quad$ & & & & \\
Need & 78 & -0.07 & 0.06 & .25 \\
$\quad$ Pittsburgh Sleep Quality Index & 81 & -0.02 & 0.03 & .61 \\
Epworth Sleepiness Scale & 79 & 0.01 & 0.05 & .86 \\
Insomnia Severity Index &
\end{tabular}

Note. All analyses were separate bivariate linear regressions 
Table 8 .

Consistency of Bed Times

\begin{tabular}{lrrrr}
\hline & N & B & SE & $p$ \\
\hline Predisposing & & & & \\
$\quad$ Age & 44 & -0.71 & 0.28 & .01 \\
Gender & 44 & -3.65 & 10.54 & .73 \\
Ethnicity & 44 & 3.71 & 21.23 & .86 \\
Education & 44 & 5.89 & 11.43 & .61 \\
& & & & \\
Enabling & & & & \\
$\quad$ Employment & 44 & -3.16 & 4.69 & .50 \\
Insurance & 44 & 0.50 & 8.09 & .95 \\
Marital Status & 44 & -4.93 & 8.90 & .58 \\
$\quad$ Number of Health Problems & 44 & 0.15 & 1.52 & .92 \\
Beck Anxiety Inventory & 42 & 0.13 & 0.40 & .74 \\
Center for Epidemiologic & & & & \\
Studies Depression Scale-Revised & 44 & 0.72 & 0.37 & .06 \\
$\quad$ & & & & \\
Need & & & & \\
$\quad$ Pittsburgh Sleep Quality Index & 43 & 1.34 & 1.24 & .29 \\
$\quad$ Epworth Sleepiness Scale & 44 & -0.18 & 0.84 & .84 \\
Insomnia Severity Index & 44 & 1.39 & 0.98 & .16 \\
\hline
\end{tabular}

Note. All analyses were separate bivariate linear regressions 
Table 9.

Consistency of Wake Times

\begin{tabular}{lrrrr}
\hline & $\mathrm{N}$ & $\mathrm{B}$ & $\mathrm{SE}$ & $p$ \\
\hline Predisposing & & & & \\
$\quad$ Age & 44 & -0.56 & 0.25 & .03 \\
Gender & 44 & -7.00 & 9.36 & .46 \\
Ethnicity & 44 & 0.08 & 18.96 & .997 \\
Education & 44 & -6.07 & 10.20 & .56 \\
& & & & \\
Enabling & & & & \\
$\quad$ Employment & 44 & 1.74 & 4.20 & .68 \\
Insurance & 44 & 3.11 & 7.21 & .67 \\
$\quad$ Marital Status & 44 & -7.46 & 7.89 & .35 \\
$\quad$ Number of Health Problems & 44 & -0.68 & 1.36 & .62 \\
Beck Anxiety Inventory & 42 & 0.27 & 0.46 & .56 \\
Center for Epidemiologic & 44 & 0.68 & 0.33 & .045 \\
$\quad$ Studies Depression Scale-Revised & & & & \\
$\quad$ & & & & \\
Need & & & & \\
$\quad$ Pittsburgh Sleep Quality Index & 43 & 0.53 & 1.12 & .64 \\
$\quad$ Epworth Sleepiness Scale & 44 & -0.004 & 0.75 & .996 \\
Insomnia Severity Index & 44 & 0.33 & 0.90 & .72 \\
\hline
\end{tabular}

Note. All analyses were separate bivariate linear regressions 
Table 10.

Predicting Consistency of Wake Times

Step 1.

Step 2.

Hierarchical Linear Regression

Age

Age

R-Square

$10 \quad 4.89$

F $\quad B$

B SE

$S E$

t-Value

$D F$

$42 \quad .03$

$\begin{array}{llll}-.56 & .25 & -2.21 & .03\end{array}$

$.15 \quad 3.50$

$-.43$

$-.43$

.27

.49

$.35 \quad 1.41$

$41 \quad .04$

Center for Epidemiologic

Studies Depression Scale-Revised

Note. Hierarchical linear regression with age entered into step one and depression symptoms entered into step two of model 


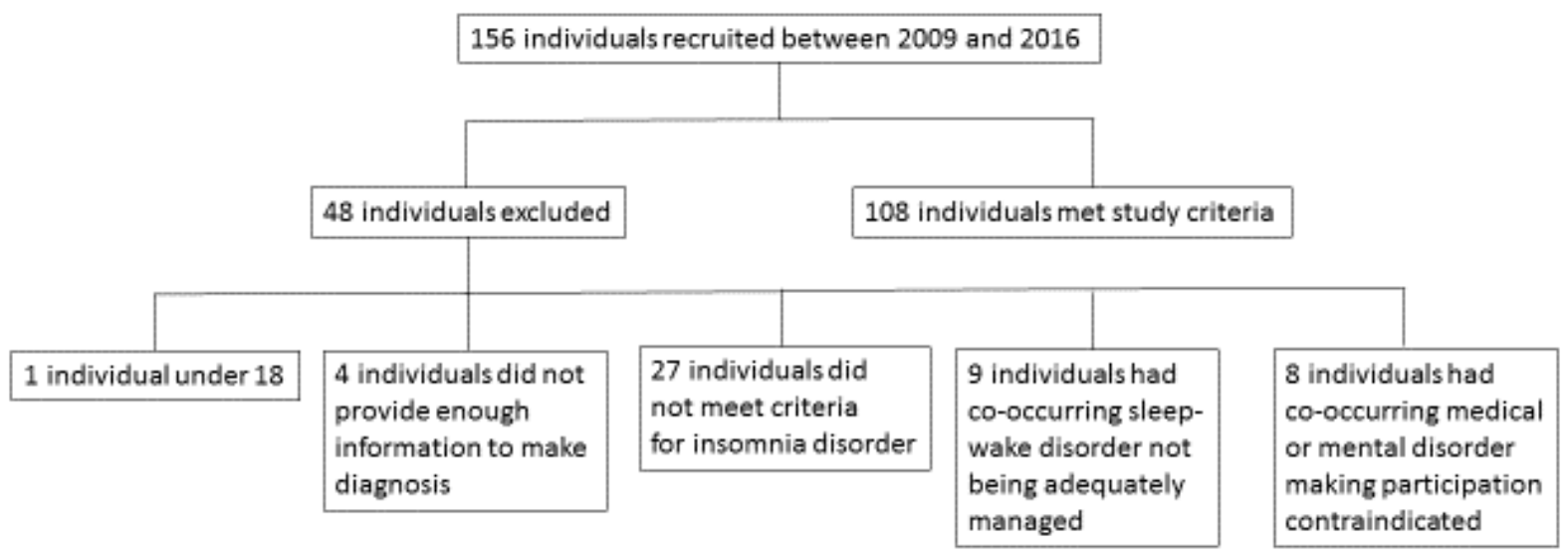

Figure 1. Reasons for exclusion throughout the recruitment time period. 


\section{Appendix A}

\section{THE EPWORTH SLEEPINESS SCALE}

Name:

Today's Date: Your Age (years):

Your sex $($ male $=\mathrm{M}$; female $=\mathrm{F})$ :

How likely are you to doze off or fall asleep in the following situations, in contrast to feeling just tired? This refers to your usual way of life in the past week. Even if you have not done some of these things recently try to work out how they would have affected you. Use the following scale to choose the most appropriate number for each situation:

$0=$ would never doze

$1=$ slight chance of dozing

$2=$ moderate chance of dozing

$3=$ high chance of dozing

\section{Situation}

Sitting and reading

Watching TV

Sitting, inactive in a public place (e.g. a theater or a meeting) As a passenger in a car for an hour without a break Lying down to rest in the afternoon when circumstances permit Sitting and talking to someone Sitting quietly after a lunch without alcohol In a car, while stopped for a few minutes in the traffic
Chance of Dozing

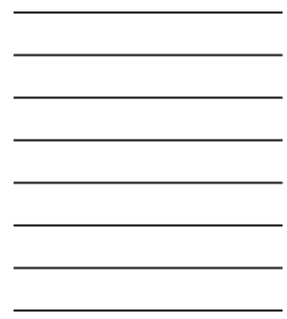

Thank you for your cooperation 


\section{Appendix B}

\section{Insomnia Severity Index (ISI)}

Name:

Date:

1. Please rate the current (i.e., last week) SEVERITY of your insomnia problem(s).

\begin{tabular}{ccccc}
$\mathbf{1 5 - 3 0 \mathrm { min }}$ & $\mathbf{3 0 - 4 5}$ & $\mathbf{4 5 - 9 0}$ & $\mathbf{9 0 - 1 2 0}$ & $>\mathbf{1 2 0}$ \\
None & Mild & Moderate & Severe & Very \\
\hline 0 & 1 & 2 & 3 & 4 \\
0 & 1 & 2 & 3 & 4 \\
$y:$ & 1 & 2 & 3 & 4
\end{tabular}

2. How SATISFIED/dissatisfied are you with your current sleep pattern?

\begin{tabular}{ccccc} 
Very Satisfied & & & Very Dissatisfied \\
\hline 0 & 1 & 2 & 3 & 4
\end{tabular}

3. To what extent do you consider your sleep problem to INTERFERE with your daily functioning (e.g. daytime fatigue, ability to function at work/daily chores, concentration, memory, mood, etc.).

\begin{tabular}{ccccc}
$\begin{array}{l}\text { Not at all } \\
\text { Interfering }\end{array}$ & A Little & Somewhat & Much & $\begin{array}{c}\text { Very Much } \\
\text { Interfering }\end{array}$ \\
\hline 0 & 1 & 2 & 3 & 4
\end{tabular}

4. How NOTICEABLE to others do you think your sleeping problem is in terms of impairing the quality of your life?

\begin{tabular}{ccccc}
$\begin{array}{l}\text { Not at all } \\
\text { Noticeable }\end{array}$ & Barely & Somewhat & Much & $\begin{array}{c}\text { Very Much } \\
\text { Noticeable }\end{array}$ \\
\hline 0 & 1 & 2 & 3 & 4
\end{tabular}

5. How WORRIED/distressed are you about your current sleep problem?

\begin{tabular}{ccccc} 
Not at all & A Little & Somewhat & Much & Very Much \\
\hline 0 & 1 & 2 & 3 & 4
\end{tabular}




\section{Appendix C}

\section{The Pittsburgh Sleep Quality Index (PSQI)}

Instructions: The following questions relate to your usial sleep habits during the past month only. Your answers should indicate the most accurate reply for the majorlty of days and nights in the past month. Please answer all questions. During the past month,

1. When have you ustally gone to bed?

2. How long (in minutes) has it taken you to fall asleep each night?

3. When have you usually gotten up in the moming?

4. How many hours of actual sleep do you get at night? (This may be different than the number of hours you spend in bed)

\begin{tabular}{|c|c|c|c|c|c|}
\hline \multicolumn{2}{|c|}{$\begin{array}{l}\text { 5. During the past month, how often have you } \\
\text { had trouble sleeping because you... }\end{array}$} & $\begin{array}{l}\text { Not during } \\
\text { the past } \\
\text { month (0) }\end{array}$ & $\begin{array}{l}\text { Less than } \\
\text { once a } \\
\text { week (1) }\end{array}$ & $\begin{array}{c}\text { Once or } \\
\text { twice a } \\
\text { week (2) }\end{array}$ & $\begin{array}{c}\text { Three or } \\
\text { more times } \\
\text { week (3) }\end{array}$ \\
\hline \multicolumn{6}{|c|}{ a. Cannot get to sleep within 30 minutes } \\
\hline \multicolumn{6}{|c|}{ b. Wake up in the middle of the night or early morning } \\
\hline \multicolumn{6}{|c|}{ c. Have tn get up to use the bathroom } \\
\hline \multicolumn{6}{|c|}{ d. Cannot breathe comfortably } \\
\hline \multicolumn{6}{|c|}{ e. Cough or snore loudly } \\
\hline \multicolumn{6}{|c|}{ f. Foel too coild } \\
\hline \multicolumn{6}{|c|}{ 8. Feel too hot } \\
\hline \multicolumn{6}{|c|}{ h. Have bad dreams } \\
\hline \multicolumn{6}{|c|}{ L. Have pain } \\
\hline \multicolumn{6}{|c|}{$\begin{array}{l}\text { J. Other reason(s), please describe, including how often you } \\
\text { have had trouble sleeping because of this reason(s): }\end{array}$} \\
\hline \multicolumn{6}{|c|}{$\begin{array}{l}\text { 6. During the past month, how often have you taben medicine } \\
\text { (prescribed or "over the counter") to help you sleep? }\end{array}$} \\
\hline \multicolumn{6}{|c|}{$\begin{array}{l}\text { 7. Durng the past month, how often have you had trouble staying } \\
\text { awake while driving, eating meals, or engapging in sockal activity? }\end{array}$} \\
\hline \multicolumn{6}{|c|}{$\begin{array}{l}\text { 8. During the past month, how mush of a problem has it been for } \\
\text { you to keep up enthuslasm to get things done? }\end{array}$} \\
\hline & & $\begin{array}{c}\text { Very } \\
\text { good }(0)\end{array}$ & $\begin{array}{l}\text { Fairly } \\
\text { good (1) }\end{array}$ & $\begin{array}{c}\text { Fairly } \\
\text { bad (2) }\end{array}$ & $\begin{array}{c}\text { Very } \\
\text { bad (3) }\end{array}$ \\
\hline \multicolumn{6}{|c|}{$\begin{array}{l}\text { 9. During the past month, how would you rate your sleep } \\
\text { quality overall? }\end{array}$} \\
\hline Component 1 & \multicolumn{5}{|c|}{ 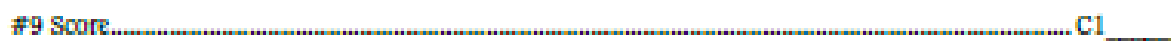 } \\
\hline Component 2 & \multicolumn{5}{|c|}{$\begin{array}{l}\text { \#2 Soore ( }=15 \mathrm{~min}=0 ; 16-30 \mathrm{~min}=1 ; 31-60 \mathrm{~min}=2,>60 \mathrm{~min}=3 \text { ) }+ \text { \#5a Score } \\
\text { (if sum is equal } 0=0 ; 1-2=1 ; 3-4=2 ; 5-6=3 \text { )..... }\end{array}$} \\
\hline Component 3 & \multicolumn{5}{|c|}{ \#4 Score $(>7=0 ; 6-7=1 ; 5-6=2 ;<5=3)$} \\
\hline Component 4 & \multicolumn{5}{|c|}{ (tntal \# of hours aslecp)/(total \# of hours in bed) $\times 100$} \\
\hline Component 5 & \multicolumn{5}{|c|}{ 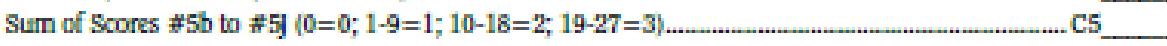 } \\
\hline Component 6 & \multicolumn{5}{|c|}{ \#6 Score . } \\
\hline Component 7 & \multicolumn{5}{|c|}{ \#7 Score + \#8 Score $(0=0 ; 1-2=1 ; 3-4=2 ; 5-6=3)$} \\
\hline
\end{tabular}




\section{Appendix D}

Name:

Date:

Below is a list of the ways you might have felt or behaved. Please check the boxes to tell me how often you have felt this way in the past week or so.

\begin{tabular}{|c|c|c|c|c|c|}
\hline \multirow[b]{2}{*}{ DURING THE PAST WEEK: } & \multicolumn{4}{|c|}{ Last Week } & \multirow{2}{*}{$\begin{array}{l}\text { Nearly } \\
\text { Every } \\
\text { Day for } \\
2 \text { Weeks }\end{array}$} \\
\hline & $\begin{array}{l}\text { Not at All } \\
\text { or Less } \\
\text { Than } 1 \\
\text { Day }\end{array}$ & 1-2 Days & 3-4 Days & 5-7 Days & \\
\hline 1. My appetite was poor. & & & & & \\
\hline 2. I could not shake off the blues. & & & & & \\
\hline $\begin{array}{l}\text { 3. I had trouble keeping my mind } \\
\text { on what I was doing. }\end{array}$ & & & & & \\
\hline 4. I felt depressed. & & & & & \\
\hline 5. My sleep was restless. & & & & & \\
\hline 6. I felt sad. & & & & & \\
\hline 7. I could not get going. & & & & & \\
\hline 8. Nothing made me happy. & & & & & \\
\hline 9. I felt like a bad person. & & & & & \\
\hline $\begin{array}{l}\text { 10. I lost interest in my usual } \\
\text { activities. }\end{array}$ & & & & & \\
\hline 11. I slept much more than usual. & & & & & \\
\hline $\begin{array}{l}\text { 12. I felt like I was moving too } \\
\text { slowly. }\end{array}$ & & & & & \\
\hline 13. I felt fidgety. & & & & & \\
\hline 14. I wished I were dead. & & & & & \\
\hline 15. I wanted to hurt myself. & & & & & \\
\hline 16. I was tired all the time. & & & & & \\
\hline 17. I did not like myself. & & & & & \\
\hline $\begin{array}{l}\text { 18. I lost a lot of weight without } \\
\text { trying to. }\end{array}$ & & & & & \\
\hline $\begin{array}{l}\text { 19. I had a lot of trouble getting to } \\
\text { sleep. }\end{array}$ & & & & & \\
\hline $\begin{array}{l}\text { 20. I could not focus on the } \\
\text { important things. }\end{array}$ & & & & & \\
\hline
\end{tabular}




\section{Appendix E}

Your initials:

Your clinician's name

Prescription this week:
WVU Insomnia Team

口 Toll free voice mail (866) 535-3343 x 31614

$\square$ Fax in Psychology Dept (304) 293-4225

$\square$ Fax in Family Medicine (304) 598-6905

(2)

COMPLETE AT NIGHT in reference to today

Sleep Diary

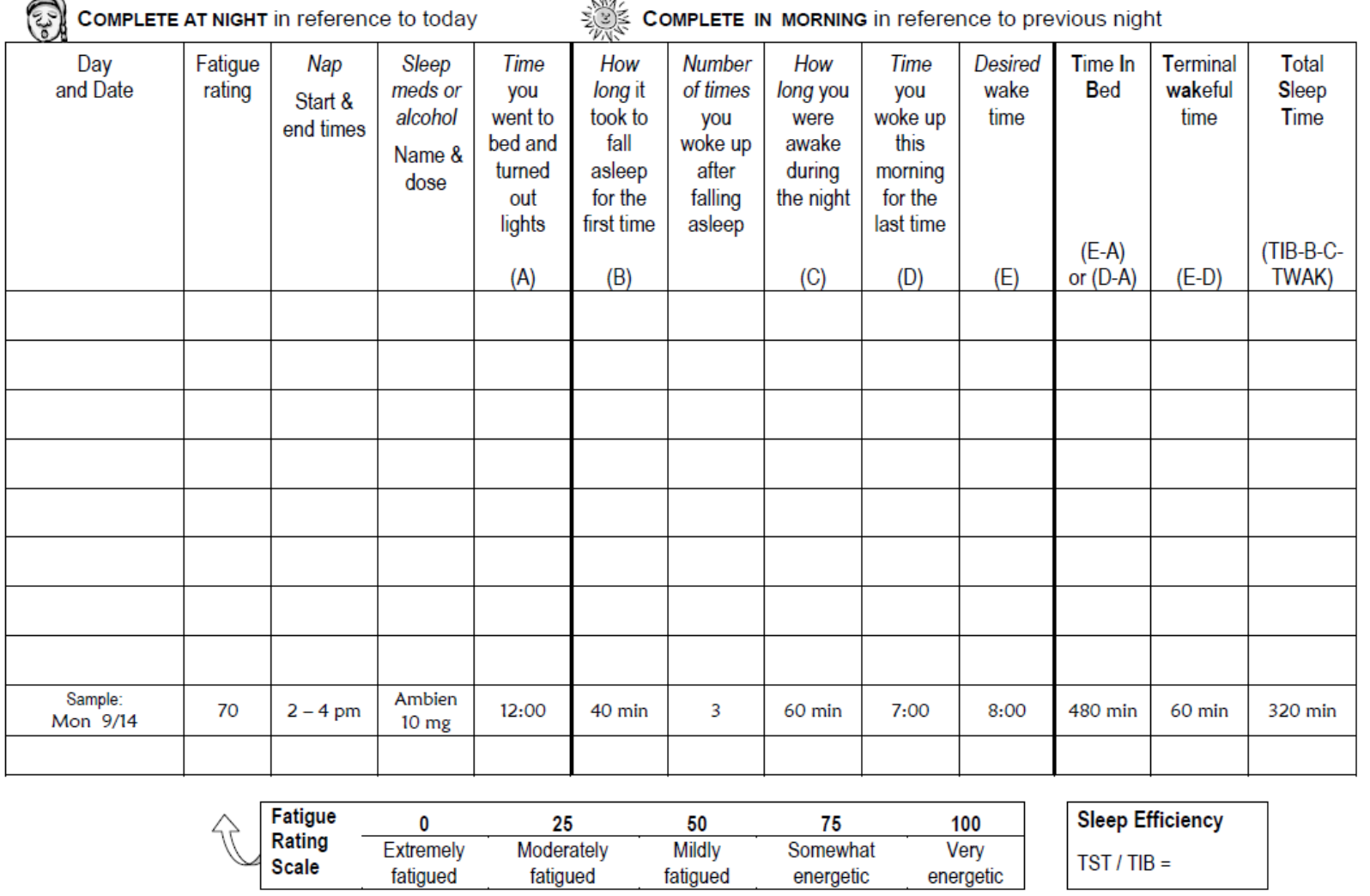

\section{Appendix F}




\section{Biographical Questionnaire}

Name:

Age:

Marital Status (circle one)

\section{Single Married Divorced Separated Widowed}

If married, Spouse's occupation:

Number of Children:

How many living with you:

Highest level of education completed?

Family Doctor:

Employment Status: (check one)

\begin{tabular}{|c|c|c|}
\hline Working & Retired & Disabled \\
\hline Student & Volunteer & Other \\
\hline
\end{tabular}

Occupation:

Person to contact in case of an emergency:

Name:

Phone Number:

Reason for visit today?

Have you had treatment for this before today?

If Yes:

Type of treatment:
Did treatment help? 


\section{Biographical Questionnaire}

If the reason for your visit is insomnia, please answer:

At what age did you first experience insomnia?

(Note: It might be helpful to think back to important events in your life, and consider whether or not you had insomnia at that time.)

At what age did your current problems with insomnia began?

If it has been less than 2 years:

How long ago did your current problems with insomnia begin? years months ago 


\section{Appendix G}

\section{MEDICAL HISTORY INFORMATION FORM}

Current weight:

Current height:

Weight 5 years ago:
Name:

Date:

BMI:

List of medications:

\begin{tabular}{|l|l|l|l|} 
Med & \multicolumn{2}{c}{ Dose Reason taking it } \\
\hline & & & \\
\hline & & & \\
\hline & & & \\
\hline & & & \\
\hline & & & \\
\hline & & & \\
\hline & & & \\
\hline & & & \\
\hline & & & \\
\hline & & & \\
\hline & & & \\
\hline
\end{tabular}

Put checkmark in the box:

a Head injury

a Hemorrhage

a Meningitis

a Migraine

a Multiple Sclerosis

a Parkinson's

a Seizures

a Stroke

a Shingles

a Chest pain

口 Irregular Heart Rhythm

a Congestive Heart Failure

a Heart Attack

a Vision problems

a Blood clots

a Asthma a Colitis

a Constipation

a Gastric Ulcer Disease

a Gastric bleeding

a Pancreatitis

a Heartburn

a Esophageal Reflux

a Cystitis

a Kidney Stones

a Menopause

a Ovarian Cysts

a Pelvic

Inflammatory

Disease

a Kidney failure

a Blood disorders

a Chronic Pain a Pneumonia

a Tuberculosis

a Cancer

a Diabetes

a Thyroid problems

a Obesity

a Gout

a Arthritis

a Fibromyalgia

a HIV disease

a Psoriasis

a Hives or rashes

a Dental problems

a Grinding teeth

a Sleep Apnea

a Restless Legs

a Hepatitis

口 Liver Disease

Other:

List Surgeries with dates: 